\author{
David Ashton \\ Department of Accounting and Finance \\ Bristol University \\ Bristol BS8 1TN, UK \\ david.ashton@bristol.ac.uk \\ Pengguo Wang \\ Xfi Centre for Finance and Investment \\ University of Exeter \\ Exeter EX4 4ST \\ p.wang@exeter.ac.uk
}

January 2015

\title{
Acknowledgements
}

The authors acknowledge many helpful comments received from participants from AAA, EAA and BAA annual meetings, Manchester University, Bristol University, Strathclyde University, Loughborough University and Imperial College London for the early versions of the paper. We would also like to thank James Ohlson, Ken Peasnell, Martin Walker, Kenton Yee and Bharat Sarath (AAA discussant) for their constructive suggestions. This paper has also benefitted from the comments of two anonymous referees as well as from an associate editor and Vivien Beattie (the editor). Corresponding author: Pengguo Wang. 


\title{
Conservatism in Residual Income Models: Theory and Supporting Evidence
}

\begin{abstract}
In this paper, we develop a framework for evaluating the impact of conservative accounting on the structure of residual income models of equity valuation. We explore specific examples of both unconditional and conditional conservatism and observe a common mathematical structure. We proceed to generalise our model and identify the joint dependency of conservatism and the persistence of abnormal earnings on the weights attached to book values, earnings and dividends. We are able to show theoretically the likely numerical impact of conservatism on price-earnings ratios and under valuations produced by residual income models. We investigate empirically the interaction between conservatism and persistence and find they accord well with the theory developed. We briefly discuss the implications for testing of the effect of conservatism on valuation and linear information dynamics.
\end{abstract}

Keywords: Accounting conservatism, Equity valuation, Residual income models, Linear information dynamics

JEL classification: M41; G12 


\section{Conservatism in Residual Income Models: Theory and Supporting Evidence}

\section{Introduction}

The principle of accounting conservatism remains a pervasive guiding constraint in the recognition of asset values and income. Conservatism involves an asymmetric treatment of gains and losses (Feltham and Ohlson (1995, 1996), Ohlson (1995), Basu (1997), Beaver and Ryan (2005)). It manifests itself in a behavior that understates equity book value or requires "a stronger verifiability requirement for the recognition of gains than for the recognition of losses" (Watts (2003)). In its implementation, conservatism drives a wedge between reported equity values and market values. An early stream of empirical literature (Amir and Lev (1996), Penman (1996, 1998), Barth et al. (1998), Collins et al. (1999), Francis and Schipper (1999)) have investigated the link between market prices, book values, earnings and dividends. However, this research has met with mixed success. Regression tests exploring this link frequently produce coefficients that have been difficult to interpret as regards both their sign and magnitude.

In this paper, we are primarily concerned with the impact of both conditional and unconditional conservatism on residual income models of equity valuation and information dynamics of abnormal earnings. We start by considering specific examples of accounting policies on the weights attached to book value and earnings in residual income models. We identify such a structure whereby these weights are mathematical functions of both conservatism and the persistence of abnormal earnings and where the same structure is equally applicable to conditional and unconditional conservatism. The paper by Ashton and Wang (2013) explores this same issue but concentrates on the empirical implications of conservatism. They adopt a 'top-down' approach to modelling conservatism and show how earnings conservatism leads to balance sheet conservatism. In contrast our approach can be best described as 'bottom-up'. We start by considering specific example of balance sheet conservatism and earnings conservatism before generalising the model and showing 
how the two are inextricably linked. Our emphasis throughout is on the theoretical modelling and understanding the nature of conservatism. Our work also differs strongly from most other prior studies such as Zhang (2000), and Beaver and Ryan (2005). In contrast, when Zhang (2000) examines the impact of conservatism on valuation weights on book values and (capitalised) earnings, he assumes the weights constant and independent of conservatism, whereas we model the dependency of the weights on both the persistence of abnormal earning and the degree of conservatism. Indeed, we argue that from the point of view of equity valuation models the distinction between conditional and unconditional conservatism in Beaver and Ryan (2005) is largely irrelevant, ${ }^{1}$ and that the manifestations of the two forms are inextricably linked.

Our starting point is the residual income valuation model of Ohlson (1995) in which he derives an equity valuation model based on the assumption that abnormal earnings, defined as earnings less a capital charge, are eroded over time, giving rise to the concept of unbiased accounting in which book and market values of equity converge. The difficulty with the conceptual unbiased accounting system posited by Ohlson (1995) is that it is not observable. The task in this paper is to establish the relationship between this unbiased and unobservable system and a reported system, where accounting values are possibly biased, inter alia, by conservative reporting principles. We begin by considering specific examples of unconditional and conditional conservatism. We consider the effect of different depreciation policies and the impact of historical cost accounting under inflationary conditions as examples of the former and the speed of recognition of "good" news and "bad" news, together with income smoothing as examples of the latter. Using a series of stochastic difference equations, we develop parametric relationships between a reported and observable, though possibly biased by conservatism, accounting information system and the corresponding unbiased unobservable accounting system of Ohlson (1995). We generalise our analysis to show how a common underlying mathematical structure unites these two forms of conservatism and we identify a single common

\footnotetext{
1 This does not undermine the use of the classification of conservatism in Beaver and Ryan (2005) as a conceptual framework for discussing accounting policy or the empirical classification for event studies such as carried out by Ball and Shivakumar (2005) and Basu (1997).
} 
summary measure of the degree of conservatism. Consistent with intuition, we predict that the price-to-earnings ratio, the price-to-book ratio and the return on equity are all monotonically increasing functions of this summary measure. We investigate empirically the dependency of valuation weights of book value and earnings on conservatism using US data over the period 1976-2010 and find that they accord well with the theory developed.

Our theoretical analysis also provides insights into apparently anomalous observations emerging in empirical research, such as the persistent undervaluation of market values by residual income models (Dechow et al. (1999), Myers (1999)) and the failure to detect conservatism in the linear information dynamics. Current theory suggests that conservatism should attribute a positive coefficient to lagged book value, when added to the simple autoregressive structure of residual income dynamics (Feltham and Ohlson (1995), Myers (1999)). In contrast, almost all empirical work documents a negative conservative parameter in such abnormal earnings regressions (Dechow et al. (1999), Myers (1999), Ahmed, et al. (2000), Beaver and Ryan (2000), Choi et al. (2006)). We argue that the structural form of the linear dynamics under conservatism is likely to produce misleading results under the econometric methods hitherto used.

The rest of the paper is organised as follows. In Section 2, we flesh out the detail of how conservatism modifies the structure of the Ohlson (1995) equity valuation model by considering specific examples of unconditional and conditional conservatism. This analysis leads to the observation of a common mathematical structure unifying our examples of conditional and unconditional conservatism. In Section 3, we develop a general theory of conservatism together with a simple measure of conservatism. We relate this measure of conservatism to accounting fundamentals and the price-to-book ratio, and use the insights gained from our analytical structure to explain apparent anomalies and difficulties encountered in prior empirical literature. Section 4 provides the empirical evidence to support our theoretical modeling. Section 5 concludes the paper. 


\section{Examples of Conditional and Unconditional Conservatism}

In this section, we employ the methodology of stochastic difference equations to establish the links between accounting variables and valuation functions in an unbiased system and the corresponding links between accounting variables and valuation functions in a reporting system, which is subject to the principle of conservatism. We first use specific examples to provide concrete contexts and specificity, and then demonstrate the existence of a common underlying mathematical structure encompassing these examples in the following section. We start with a review of the Ohlson (1995) framework and the concept of unbiased accounting.

\subsection{Equity Valuation and Information Dynamics in the Ohlson (1995) Framework}

Ohlson (1995) builds his residual income valuation model on three assumptions. First, a no-arbitrage condition determines the present value of future dividends or equity values, i.e. $E_{t}\left[P_{t+1}+d_{t+1}\right]=R P_{t}$, where $P_{t}$ is equity value at time $\mathrm{t}, d_{t}$ is the dividends paid (net of new capital contributions), and $R$ is one plus the (constant) cost of equity capital, $E_{t}[$.] is the expectation operator based on all available information at time $t$. Second, the clean surplus accounting relation (CSR): $b_{t}^{\prime}=b_{t-1}^{\prime}+e_{t}^{\prime}-d_{t}$, where $b_{t}^{\prime}$ and $e_{t}^{\prime}$ are respectively book values of equity and earnings at time t. Third, a linear information dynamics of abnormal earnings whereby economic rents mean revert to zero: ${ }^{2}$

$$
x_{t+1}^{\prime}=\omega x_{t}^{\prime}+\varepsilon_{x, t+1},
$$

where $x_{t}^{\prime} \equiv e_{t}^{\prime}-(R-1) b_{t-1}^{\prime}, 0 \leq \omega<1$, and $\varepsilon_{x, t+1}$ is a mean zero random error term. Ohlson then shows that the value of equity at time $t$, can be written as a weighted average of book value and dividend adjusted capitalised earnings as in equation (2):

$$
V_{t}=\frac{R(1-\omega)}{R-\omega} b_{t}^{\prime}+\frac{R \omega}{R-\omega} e_{t}^{\prime}-\frac{\omega(R-1)}{R-\omega} d_{t}
$$

\footnotetext{
${ }^{2}$ We do not consider an "other information" variable here. Accounting conservatism is a long-run property and "other information" in the standard residual income based valuation model is generally regarded as behaving as a stationary auto-regressive process, and therefore it is not expected to be critical to valuation in the long-run.
} 
The valuation weights are purely functions of the cost of equity capital and the persistence of abnormal earnings. However, the accounting information system in Ohlson (1995) is unbiased in the sense that the expected future values of book and market equity converge. The unbiased book value of equity, $b_{t}^{\prime}$, may differ from the equity price at time $\mathrm{t}$ because the book value does not take account of expected future abnormal earnings. These abnormal earnings are assumed to be eroded over time by competition (Fisher and McGowan (1983)). As a result, the above information dynamics, equation (1) and the valuation model (2) are not directly testable, unless we are prepared to accept that reported accounting numbers are an adequate representation of economic rents. Thus our immediate task is to investigate how Ohlson's (1995) hypothesised unbiased accounting system is transformed under conservative reporting principles to an accounting system that is observable. In this reporting system, the accounting will be likely biased in the sense that the expected values of long-run book and market values no longer converge.

Purely for tractability of our analysis, we initially assume that our firms are all-equity financed $^{3}$; an assumption that we will relax when we generalise our model in Section 3. We denote the hypothesised unbiased information system by $\Lambda_{t}^{\prime}=\left\{b_{\tau}^{\prime}, e_{\tau}^{\prime}\right\}, \tau=0,1,2, \ldots t$. Now suppose that the accounting information set $\Lambda_{t}$, represents a complete history of reported book values and earnings up to and including time t, i.e. $\Lambda_{t}$ is the accounting system, $\left\{b_{\tau}, e_{\tau}\right\}, \tau=0,1,2, \ldots t$, where $b_{\tau}$ and $e_{\tau}$ are respectively reported book values of equity and earnings at time $\tau$. Although these reported book values and earnings are likely biased because of accounting conservatism, we can still assume that they also follow clean surplus accounting: $b_{t}=b_{t-1}+e_{t}-d_{t}$. We also assume that $\Lambda_{t}$ and $\Lambda_{t}^{\prime}$ are related via the cash flow triple $\left\{Y_{t}, I_{t}, d_{t}\right\}$, where $Y_{t}$ denotes cash flow from operations, and $I_{t}$ represents the total investment including investments in both tangible and intangible assets at time t. With this notation, we turn our attention to how unbiased accounting might be modified by a

\footnotetext{
${ }^{3}$ Alternatively we could interpret this part of our analysis as comparing two identical firms save for differences in accounting policies, with references to cash flows referring to only the equity portion of these.
} 
reporting system subject to the principles of conservatism.

\subsection{Unconditional Conservative Systems}

Feltham and Ohlson (1996) establish a link between depreciation policy and valuation weights of accounting variables. Hence a natural starting point for exploring conservative accounting systems is to re-examine the case where the actual depreciation rate $\alpha$ differs from the economic depreciation rate $\alpha^{\prime}$ such that $\alpha>(<) \alpha^{\prime}$, corresponds to over (under) depreciation. We start by recasting this link using stochastic difference equations linking the accounting variables in $\Lambda_{t}$ and $\Lambda_{t}^{\prime}$ to cash flows before we go on to generalise this structure to other examples of both conditional and unconditional conservatism.

Specifically, we assume the following relationships hold: ${ }^{4}$

$$
b_{t}^{\prime}-\left(1-\alpha^{\prime}\right) b_{t-1}^{\prime}=I_{t}=b_{t}-(1-\alpha) b_{t-1}
$$

Here $0 \leq \alpha^{\prime}$ and $\alpha<1$. For parsimony of the analysis, we also assume $I_{t}$ which represents the equity portion of investment follows a stochastic growth path:

$$
I_{t}=(1+g) I_{t-1}+u_{t},
$$

where $\mathrm{g} \geq 0$ represents long-run average growth and $u_{t}$ is a random error term with expectation zero and assumed to be serially independent. ${ }^{5}$ The equations as specified in (3) and (4) are thus stochastic difference equations. It follows that the long-run equilibrium relationship is shown as in equation (5), where proofs of equation (5) and the following three equations (6)-(8) can be found in Appendix A. The expected long-run equilibrium values of the unbiased book values in terms of the corresponding

\footnotetext{
${ }^{4}$ This structure is more general than it may appear at first sight. We can regard $\alpha$ as an average or composite rate of depreciation over different classes of assets, both tangible and intangible. For example $\alpha$ may include a contribution from the expensing of intangibles investments such as R\&D or advertising. Note that $(1-\alpha)$ here is equivalent to $\delta$ (a policy parameter which determines the depreciation rate) in Feltham and Ohlson (1996 pp215). They state that 'the overdepreciation case $\delta \leq \gamma$ (the cash receipts persistence parameter) is of interest because it induces conservative accounting.' In our analysis, we do not assume the cash inflow dynamics. Therefore we do not have parameter, $\gamma$. Instead, we directly assume two policy parameters, $\alpha$ and $\alpha^{\prime}$ in both biased and unbiased accounting systems.

${ }^{5}$ Value is determined purely by investment policy and the model is thus consistent with dividend displacement (Miller and Modigliani (1961)). We also assume, as do most residual income models that risk is held constant.
} 
reported values are:

$$
E\left[b_{t}^{\prime} \mid \Lambda_{t}\right]=\frac{g+\alpha}{g+\alpha^{\prime}} b_{t}=\left(1+\frac{\alpha-\alpha^{\prime}}{\alpha^{\prime}+g}\right) b_{t}
$$

Given the above relationship between book values in the two accounting systems, we can also establish a relationship between the earnings in the two systems. Equating cash inflows in the two systems $e_{t}^{\prime}+\alpha^{\prime} b_{t-1}^{\prime}=Y_{t}=e_{t}+\alpha b_{t-1}$, we have:

$$
E\left[e_{t}^{\prime} \mid \Lambda_{t}\right]=e_{t}+\frac{\alpha-\alpha^{\prime}}{\alpha^{\prime}+g}\left(b_{t}-b_{t-1}\right)
$$

Note that CSR implies the cash identity: $Y_{t}=I_{t}+d_{t}$. Equation (5) shows that whenever the reported accounting depreciation rate $(\alpha)$ is greater than the economic depreciation rate $\left(\alpha^{\prime}\right)$ accounting is conservative: the reported book value understates unbiased book values (or balance sheet conservatism). From equation (6), we see that the reported earnings are also understated relative to unbiased economic earnings whenever accounting is conservative (or earnings conservatism). By direct substitution in to equation (2), together with CSR, the expected value of equity given the reported financial information set $\Lambda_{t}, E\left[V_{t} \mid \Lambda_{t}\right]$, can be written as:

$$
E\left[V_{t} \mid \Lambda_{t}\right]=\frac{R(1-\omega)}{R-\omega}\left(1+\frac{\alpha-\alpha^{\prime}}{\alpha^{\prime}+g}\right) b_{t}+\frac{R \omega}{R-\omega}\left(1+\frac{\alpha-\alpha^{\prime}}{\alpha^{\prime}+g}\right) e_{t}-\left(\frac{(R-1) \omega}{R-\omega}+\frac{R \omega}{R-\omega} \frac{\alpha-\alpha^{\prime}}{\alpha^{\prime}+g}\right) d_{t}
$$

If we let $\chi_{U}=\frac{\alpha-\alpha^{\prime}}{\alpha^{\prime}+g}$, equation (7) can be written more succinctly as:

$$
E\left[V_{t} \mid \Lambda_{t}\right]=\frac{R(1-\omega)}{R-\omega}\left(1+\chi_{U}\right) b_{t}+\frac{R \omega}{R-\omega}\left(1+\chi_{U}\right) e_{t}-\left(\frac{(R-1) \omega+R \omega \chi_{U}}{R-\omega}\right) d_{t}
$$

The parameter $\chi_{U}$ is a convenient summary measure of the application of this unconditional conservative policy. It is a monotonic increasing function of $\left(\alpha-\alpha^{\prime}\right)$. If $\alpha>\alpha^{\prime}, \chi_{U}>0$ and if $\alpha<\alpha^{\prime}, \chi_{U}<0$, while $\alpha^{\prime}=\alpha$ implies $\chi_{U}=0$ and the absence of conservatism. The $g$ in the denominator is merely a convenient way of summarising the impact of the past application of overdepreciation in our simple closed form model. 
In contrast to the valuation model in equation (2), in the modified valuation model the weights on book value, earnings and dividends in equation (8) are now functions of the degree of conservatism, $\chi_{U}$, as well as the persistence of abnormal earnings and the cost of capital. Consistent with intuition, equation (8) shows that as our summary measure of conservatism $\chi_{U}$ increases, the weights attached to book value and earnings increase. In contrast, our model predicts that the weight attached to dividends (net of new capital contributions) is negative and decreases with increasing conservatism.

We can extend the above analysis to cover the case of historical cost accounting under inflation, which is also a form of unconditional conservatism. In the case of historical cost accounting under inflation, in addition to any possible effects of accelerated depreciation, the recognition of earnings is delayed because accounting earnings ignores the contribution from the appreciation of assets. We assume that reported earnings and book values satisfy the same equations as before, i.e. $b_{t}-(1-\alpha) b_{t-1}=I_{t}$ and $e_{t}+\alpha b_{t-1}=Y_{t}$. The cash flow, investment and inflation-adjusted accounting numbers, on the other hand, are linked as in the following equation system:

$$
\begin{gathered}
b_{t+1}^{\prime}=\left(1-\alpha^{\prime}\right)(1+\eta) b_{t}^{\prime}+I_{t+1}, \\
e_{t+1}^{\prime}=Y_{t+1}-\alpha^{\prime}(1+\eta) b_{t}^{\prime}+\eta b_{t}^{\prime}, \\
I_{t}=(1+g)(1+\eta) I_{t-1}+u_{t} .
\end{gathered}
$$

Here $\eta$ is the rate of inflation and $u_{t}$ is a random error term which has expectation zero and is assumed serially independent. Investment has a real growth rate $g$ in addition to any inflationary growth. The last term in the second equation, $\eta b_{t}^{\prime}$, represents the holding gain on assets. In this case inflation adjusted book values and earnings are related to reported values by the equations:

$$
\begin{gathered}
E\left[b_{t}^{\prime} \mid \Lambda_{t}\right]=\left(1+\frac{\alpha-\alpha^{\prime}+\eta\left(1-\alpha^{\prime}\right)}{\left(g+\alpha^{\prime}\right)(1+\eta)}\right) b_{t}, \\
E\left[e_{t}^{\prime} \mid \Lambda_{t}\right]=e_{t}+\left(\frac{\alpha-\alpha^{\prime}+\eta\left(1-\alpha^{\prime}\right)}{\left(g+\alpha^{\prime}\right)(1+\eta)}\right)\left(b_{t}-b_{t-1}\right) .
\end{gathered}
$$


We note that the mathematical structure of the relationship between inflation adjusted values and reported values is identical to that in equations (5) and (6), with a summary measure of the conservatism given by

$$
\chi_{U}=\frac{\alpha-\alpha^{\prime}+\eta\left(1-\alpha^{\prime}\right)}{\left(g+\alpha^{\prime}\right)(1+\eta)} .
$$

It is clear that $\chi_{U}$ increases in the rate of inflation, $\eta$. This analysis generalises earlier results found in Hughes et al. (2004) and Ashton et al. (2011). ${ }^{6}$

\subsection{Conditional Conservative Systems}

Depreciation and historical cost accounting under inflation are essentially examples of unconditional conservatism or balance sheet conservatism. We now provide an example of conditional accounting conservatism to show how a common underlying mathematical structure unites these two forms of conservatism within a residual income framework.

Conservatism also arises where the firm is cautious in the recognition of "good" news in the form of an unexpected, possibly uncertain, increases in income but speedy recognizes "bad" news in the form of an unexpected, or uncertain decrease, in income. An implication ${ }^{7}$ of this is that earnings are more positively related to current equity share returns when earnings are negative than when earnings are positive (Basu (1997), Pope and Walker (1999), Beaver and Ryan (2005), Pae et al. (2005), Givoly et al. (2007), Khan and Watts (2009), Garcia Lara et al. (2011)). Our modelling of conditional accounting conservatism echoes the assumptions underlying the empirical work in this area.

We suppose that an unbiased accounting system records a set of earnings $e_{t}^{\prime}$ according to

$$
e_{t}^{\prime}=\tilde{e}_{t}+\varepsilon_{t}
$$

\footnotetext{
${ }^{6}$ Hughes et al. (2004) examine the value relevance of accounting variables and characterise the impact of inflation on the weights that attach to the accounting items. They are primarily concerned with the question as to whether one can adjust depreciation policy in an inflationary environment to produce an unbiased valuation model. Ashton et al. (2011) examine a special case where $\alpha=\alpha^{\prime}$ and $g=0$.

${ }^{7}$ It may lead to an improved contracting, decreased litigation risk and reduced information asymmetry (Watts (2003)).
} 
where $\tilde{e}_{t}$ is the "unambiguous" portion of uncertain earnings at time $\mathrm{t}$ and $\varepsilon_{t}>0$ represents "good" news or an unanticipated increase in income and $\varepsilon_{t}<0$ represents "bad" news or an unanticipated shortfall in income. For the convenience of our modelling, we let $\varepsilon_{t}=b_{t-1} \varepsilon$, where $\mathcal{E}$ is an independent and identically distributed random variable with mean zero ${ }^{8}$. In our conservative accounting system, we suppose that earnings $e_{t}$ can be written as

$$
e_{t}=\tilde{e}_{t}+\Phi_{t}
$$

where the adjustment $\Phi_{t}$ is used to recognise the cumulative past and current impact of good or bad news that has been incorporated in the current earnings. For our convenience, we assume

$$
\Phi_{t}=\left\{\begin{array}{c}
\delta_{t}^{\prime}=\lambda^{\prime} b_{t-1} \varepsilon+\left(1-\lambda^{\prime}\right) \delta_{t-1}^{\prime} \text { if } \varepsilon<0 \\
\delta_{t}=\lambda b_{t-1} \varepsilon+(1-\lambda) \delta_{t-1} \text { if } \varepsilon \geq 0
\end{array} \text { and } \lambda, \lambda^{\prime} \in[0,1], \lambda^{\prime}>\lambda\right.
$$

Thus only a fraction $\lambda\left(\lambda^{\prime}\right)$ of good news (bad news) is incorporated at any time t. Under conservative accounting, the impact of any good news is recognised over a relatively long time period $\left(\lambda<\lambda^{\prime}\right)$. The greater $\left(\lambda^{\prime}-\lambda\right)$, the greater is the degree of accounting conservatism. When $\lambda^{\prime}=1$ and $\lambda=0$, bad news is incorporated immediately into earnings, while good news is ignored. By recursion $\delta_{t}$ and $\delta_{t}^{\prime}$ can be written as:

$$
\delta_{t}=\lambda \sum_{s=0}^{t-1}(1-\lambda)^{s} b_{t-s-1} \varepsilon, \text { and } \delta_{t}^{\prime}=\lambda^{\prime} \sum_{s=0}^{t-1}\left(1-\lambda^{\prime}\right)^{s} b_{t-s-1} \varepsilon
$$

Given (15), $e_{t}$ are related to $e_{t}^{\prime}$ by the following relationship:

$$
e_{t}=e_{t}^{\prime}+\Phi_{t}-b_{t-1} \varepsilon
$$

In order to summarise the history of the incorporation of news and derive a closed form solution we again make the simplifying assumption that the expected changes in book values occur at a growth rate of $g$. Given the clean surplus relationship, it follows (see Appendix A for details) from equation (17) that the transformation from the unbiased system to the reported accounting system can be written:

\footnotetext{
${ }^{8}$ While lagged book value may capture the size effect of a firm in $\varepsilon_{t}=\varepsilon b_{t-1}$, equation (17) below in fact describes the stochastic nature of return on equity.
} 


$$
E\left[e_{t}^{\prime} \mid \Lambda_{t}\right]=e_{t}+\left(\frac{\kappa(1-\lambda)}{g+\lambda}+\frac{(1-\kappa)\left(1-\lambda^{\prime}\right)}{g+\lambda^{\prime}}\right)\left(b_{t}-b_{t-1}\right)
$$

where $\kappa=E[\varepsilon \mid \varepsilon>0] .{ }^{9}$ Therefore, for whatever managerial incentives, the valuation effect of conditional conservatism is just like unconditional conservatism and delays in the recognition of increases in economic wealth in reported earnings.

Under the assumption that long-run growth is positive ensuring that $b_{0}$ and $b_{0}^{\prime}$ are insignificant compared with, $b_{t}$ and $b_{t}^{\prime}$, we can write the book value in the unbiased accounting system in terms of the reported book value as:

$$
E\left[b_{t}^{\prime} \mid \Lambda_{t}\right]=\left(1+\kappa \frac{(1-\lambda)}{g+\lambda}+(1-\kappa) \frac{\left(1-\lambda^{\prime}\right)}{g+\lambda^{\prime}}\right) b_{t}
$$

The resulting valuation equation is:

$$
\begin{aligned}
& E\left[V_{t} \mid \Lambda_{t}\right]=\frac{R(1-\omega)}{R-\omega}\left(1+\kappa \frac{(1-\lambda)}{g+\lambda}+(1-\kappa) \frac{\left(1-\lambda^{\prime}\right)}{g+\lambda^{\prime}}\right) b_{t}+\frac{R \omega}{R-\omega}\left(1+\kappa \frac{(1-\lambda)}{g+\lambda}+(1-\kappa) \frac{\left(1-\lambda^{\prime}\right)}{g+\lambda^{\prime}}\right) e_{t} \\
& -\left(\frac{(R-1) \omega}{R-\omega}+\frac{\omega R}{R-\omega}\left(\kappa \frac{(1-\lambda)}{g+\lambda}+(1-\kappa) \frac{\left(1-\lambda^{\prime}\right)}{g+\lambda^{\prime}}\right)\right) d_{t} .
\end{aligned}
$$

We note that the mathematical structure of the equations in (18), (19) and (20) assumes the same pattern as in the previous subsection with the summary measure representing, in this case, conditional conservatism taking the form: $\chi_{C}=\kappa \frac{(1-\lambda)}{g+\lambda}+(1-\kappa) \frac{\left(1-\lambda^{\prime}\right)}{g+\lambda^{\prime}}$. Thus equation (20) can be rewritten as:

$$
E\left[V_{t} \mid \Lambda_{t}\right]=\frac{R(1-\omega)}{R-\omega}\left(1+\chi_{C}\right) b_{t}+\frac{R \omega}{R-\omega}\left(1+\chi_{C}\right) e_{t}-\left(\frac{(R-1) \omega+R \omega \chi_{C}}{R-\omega}\right) d_{t}
$$

In this case, the policy giving rise to conservatism is attributable to the relative speeds in the recognition of future negative and positive earnings. Given the "uncertainty" of the ambiguous portion of return on equity, the degree of conservatism depends on the "speed" with which this ambiguous portion of earnings is incorporated into reported earnings and the volatility or the arrival

\footnotetext{
${ }^{9}$ In the case of $\mathcal{E}$ being distributed as a zero mean normal with standard deviation $\sigma, \kappa=\frac{\sigma}{\sqrt{2 \pi}}$.
} 
rate of news. Since $\chi_{C}$ can be written as $\chi_{C}=\frac{1-\lambda^{\prime}}{g+\lambda^{\prime}}+\kappa \frac{(1+g)\left(\lambda^{\prime}-\lambda\right)}{(g+\lambda)\left(g+\lambda^{\prime}\right)}$, we observe that the degree of accounting conservatism increases as $\left(\lambda^{\prime}-\lambda\right)$ increases.

The policy of smoothing a growing income stream also delays the recognition of future positive earnings and is a form of conservatism. The mathematical analysis is developed in Appendix $\mathrm{B}$ and again the degree of conservatism can be summarised by a simple $\chi$-parameter.

\section{A Theoretical Model of Conservatism}

\subsection{Integrating Conditional and Unconditional Conservatism}

Although our examples of conditional and unconditional conservatism result in an apparently common mathematical structure for the valuation function, equations (8) and (21), it remains unclear how the different forms of conservatism that might be simultaneously practiced by an individual firm might manifest themselves. We also note that in their present forms our valuation functions are not directly testable. Economic depreciation rates $\left(\alpha^{\prime}\right)$ and the speed of recognition of good or bad news ( $\lambda$ or $\lambda^{\prime}$ ) are not observable. Apart from these accounting policy parameters, our measures of conservatism are also functions of some assumed long-term growth rates in investment and book values, which summarise the impact of the past history of the consistent application of conservative accounting policies.

If we reflect on the underlying structure of our conditional and unconditional conservatism, we see that they essentially have the same impact on earnings and book values. In the case of earnings conservatism, as in equation (18), the adjustment to reported earnings takes the form:

$$
E\left[e_{t}^{\prime} \mid \Lambda_{t}\right]=e_{t}+\chi_{C}\left(b_{t}-b_{t-1}\right) .
$$

Equation (22) together with the clean surplus relationship and the invariance of dividends in the two systems imply: 


$$
E\left[e_{t}^{\prime} \mid \Lambda_{t}\right]-\left(E\left[b_{t}^{\prime} \mid \Lambda_{t}\right]-E\left[b_{t-1}^{\prime} \mid \Lambda_{t}\right]\right)=e_{t}+\chi_{C}\left(b_{t}-b_{t-1}\right)-\left(E\left[b_{t}^{\prime} \mid \Lambda_{t}\right]-E\left[b_{t-1}^{\prime} \mid \Lambda_{t}\right]\right),
$$

from which it follows that:

$$
E\left[b_{t}^{\prime} \mid \Lambda_{t}\right]-E\left[b_{t-1}^{\prime} \mid \Lambda_{t}\right]=\left(1+\chi_{C}\right)\left(b_{t}-b_{t-1}\right)
$$

or

$$
E\left[b_{t}^{\prime} \mid \Lambda_{t}\right]=\left(1+\chi_{C}\right) b_{t}
$$

which characterises balance sheet conservatism. On the other hand, we have from our equation for balance sheet conservatism that:

$$
E\left[b_{t}^{\prime} \mid \Lambda_{t}\right]=\left(1+\chi_{U}\right) b_{t}
$$

and hence that:

$$
E\left[b_{t}^{\prime} \mid \Lambda_{t}\right]-E\left[b_{t-1}^{\prime} \mid \Lambda_{t}\right]=\left(1+\chi_{U}\right)\left(b_{t}-b_{t-1}\right)
$$

and application of clean surplus leads us back to an equation of the form (22), $E\left[e_{t}^{\prime} \mid \Lambda_{t}\right]=e_{t}+\chi_{U}\left(b_{t}-b_{t-1}\right)$, which illustrates earnings conservatism.

The reason why the parametric models of conservatism assume the same mathematical form is that they both have their origins in the very nature of conservative policies and the clean surplus accounting. Both in the case of conditional, and of unconditional conservatism, the effect of conservatism is to delay the recognition of the increases in economic wealth or recognise the expected future losses in current income. In the case of accelerated depreciation we are simultaneously delaying the recognition of true asset values and hence of earnings. In the case of the cautious recognition of good news, we are again likely delaying the recognition of earnings or recognising possible loss immediately and hence of shareholders' wealth. The algebra in equations (22) to (27) neatly captures this delay.

We also have a number of interesting observations. First, a weighted average of equations (8) and (21) gives 


$$
E\left[V_{t} \mid \Lambda_{t}\right]=\frac{R(1-\omega)}{R-\omega}(1+\chi) b_{t}+\frac{R \omega}{R-\omega}(1+\chi) e_{t}-\left(\frac{(R-1) \omega+R \omega \chi}{R-\omega}\right) d_{t}
$$

where $\chi=w \chi_{C}+(1-w) \chi_{U}$, and $w$ and $1-w$ are the relative weights on the two forms of conservatism, suggesting that different conservative policies applied to different asset classes form a natural weighting ${ }^{10}$ and are inextricably connected. We also note in this context that in equation (14) the measure of conservatism is just the sum of the measure for accelerated depreciation and the measure for inflation applied independently to the same asset.

Second, equation (28) can be written in the form

$$
E\left[V_{t} \mid \Lambda_{t}\right]=\left(\frac{R}{R-\omega}(1+\chi)-\beta\right) b_{t}+\beta e_{t}-\left(\frac{(R-1) \omega+R \omega \chi}{R-\omega}\right) d_{t}
$$

with $\beta=\frac{R \omega}{R-\omega}(1+\chi)$, emphasising the intractability of separating balance sheet conservatism from earnings conservatism. This is also consistent with Pope and Walker (1999) who argue that balance sheet conservatism reduces the measures of earnings conservatism in valuation.

Third, equation (29) can be also written in the following form:

$$
E\left[V_{t} \mid \Lambda_{t}\right]=\left[\frac{R(1-\omega)}{R-\omega} b_{t}+\frac{R \omega}{R-\omega} e_{t}-\frac{(R-1) \omega}{R-\omega} d_{t}\right]+\frac{\chi R}{R-\omega}\left(b_{t}-\omega b_{t-1}\right)
$$

We see that the former expression is equal to the original Ohlson model (equation (2)) plus an additional term that controls for the influence of conservatism on the expected economic value of equity. In other words, the expected value of equity can be divided into two parts: the value in the absence of conservatism ( the first three terms) and the value of accounting conservatism, represented by the final term. ${ }^{11}$

We now turn our attention to identifying the structure of the linear information dynamics that is consistent with our revised valuation model. Prior empirical research reports a failure to detect

\footnotetext{
${ }^{10}$ Strictly $\chi$ should carry a time subscript, since both forms of conservatism are asset or income specific and hence time dependent. However provided that the firm's policy is applied consistently across asset classes and the long run asset mix remains on average constant, we can interpet $\chi$ as summarising the long run policy of the firm.

${ }^{11}$ Yee (2005) assumes a mean-reverting process of abnormal earnings. The conservative adjustment term in his model is a non-zero constant rather than time-varying as in equation (30).
} 
conservatism in the structure of the linear information dynamics. In this research, investigators invariably use a model as in equation (31) below, with the assumption that conservatism should manifest itself in a positive coefficient $\omega_{2}$ attached to the book value term:

or

$$
\begin{aligned}
& x_{t+1}=\omega_{1} x_{t}+\omega_{2} b_{t}+\varepsilon_{x, t+1}, \\
& x_{t+1}=\omega_{1} x_{t}+\omega_{2} b_{t-1}+\varepsilon_{x, t+1}
\end{aligned}
$$

In our review of the published literature, we find that all such empirical work documents a negative value attached to the book value term (Dechow et al. (1999), Myers (1999), Ahmed, et al. (2000), Beaver and Ryan (2000), Choi et al. (2006)).

The linear dynamics consistent with valuation equation (28) can be obtained assuming efficient pricing of equity, $R E\left[V_{t} \mid \Lambda_{t}\right]=E\left[V_{t+1}+d_{t+1} \mid \Lambda_{t}\right]$ and CSR:

$$
E\left[x_{t+1}\right]=\omega_{1} x_{t}+\chi\left[\left(R b_{t}-b_{t+1}\right)-\omega_{1}\left(R b_{t-1}-b_{t}\right)\right]
$$

where $\omega_{1}=\omega$. A proof can be found in appendix A. We note that this last equation can also be derived directly by application of the book value and earnings transformations equations, (22) and (24), to the simple autoregressive process for abnormal earnings in the unbiased system, equation (1), confirming consistency between the valuation structure and the linear information dynamics. We note that the structure of equation (32), with a $t+1$ variable on the right-hand side does not easily lend itself to simple econometric methods ${ }^{12}$.

Our summary measure of conservatism $\chi$ refects how the conservatism that manifests itself in the accounting statements depends on the different accounting policies pursued and the past histories of the application of these policies. We have captured this past history by the simplifying assumption of a long-run growth rate $(g)$ and by simple but unobservable parameters specifying different accounting policies. Next, we provide a more useful way of specifying summary measure of conservatism $\chi$.

\footnotetext{
${ }^{12}$ Ashton and Wang (2013) get round this issue by using a variant of Lintner's (1964) dividend smoothing model to forecast $b_{t+1}$.
} 


\subsection{A Measure of Conservatism}

In an unbiased system, we have the expected convergence of market and book values, $\lim _{s \rightarrow \infty} E_{t}\left[P_{t+s}\right]=\lim _{s \rightarrow \infty} E_{t}\left[b_{t+s}^{\prime}\right]$. Applying equation (25) or (26), we have $\lim _{s \rightarrow \infty} E_{t}\left[P_{t+s}\right]=(1+\chi) \lim _{s \rightarrow \infty} E_{t}\left[b_{t+s}\right]$. Hence, our measure

$$
\chi=\lim _{s \rightarrow \infty} \frac{E_{t}\left[P_{t+s}\right]}{E_{t}\left[b_{t+s}\right]}-1,
$$

and $\chi$ represents the long-run expected value of unrecorded goodwill as a fraction of reported book value $^{13}$. If we assume that book values grow on average at a rate of $\mathrm{g}$, it enables us to establish further relationships between accounting fundamentals and our summary measure $\chi$. The long-run equilibrium one-year ahead earnings yield $e y$, as defined by

$$
e y \equiv \lim _{s \rightarrow \infty} \frac{E_{t}\left[e_{t+s+1}\right]}{E_{t}\left[P_{t+s}\right]}=\lim _{s \rightarrow \infty} \frac{E_{t}\left[e_{t+s+1}^{\prime}\right]-g \chi E\left[b_{t+s}\right]}{E_{t}\left[P_{t+s}\right]}=R-1-\frac{\chi g}{1+\chi} .
$$

We note that $\lim _{s \rightarrow \infty} E_{t}\left[e_{t+s+1}^{\prime}\right]=(R-1) \lim _{s \rightarrow \infty} E_{t}\left[P_{t+s}\right]$ in an unbiased accounting system. Further, the long-run price-earnings ratio and return on equity are given by equation (35) and (36) below:

$$
\begin{gathered}
R O E \equiv \lim _{s \rightarrow \infty} \frac{E_{t}\left[e_{t+s+1}\right]}{E_{t}\left[b_{t+s}\right]}=R-1+\chi(R-1-g), \\
P E \equiv \lim _{x \rightarrow \infty} \frac{E_{t}\left[P_{t+s}\right]}{E_{t}\left[e_{t+s}\right]}=\lim _{x \rightarrow \infty} \frac{E_{t}\left[P_{t+s}\right] / E_{t}\left[b_{t+s-1}\right]}{E_{t}\left[e_{t+s}\right] / E_{t}\left[b_{t+s-1}\right]}=\frac{(1+\chi)(1+g)}{R-1+\chi(R-1-g)} .
\end{gathered}
$$

Both Ohlson and Gao (2006) and Rajan et al. (2007) derive results similar to those above, albeit from slightly different perspectives. Although their approach is somewhat different from ours, both approaches imply the return on equity is negatively related to growth under a conservative accounting policy. Ohlson and Gao (2006) argue that conservative accounting increases the market-to-book ratio with an offsetting increased expected return on equity. Our expression of ROE in equation (35) shows that the difference between the return on equity and the cost of capital is positively related to the

13 This measurement is also consistent with that given in the P D Leake Lecture to the ICAEW (Barker 2014). 
degree of conservatism given a moderate growth rate. It summarizes the main results in Rajan et al. (2007), who argue that ROE is 'a function of two variables: past growth in new investments and accounting conservatism...more conservative accounting will increase ROE provided growth in new investment has been moderate'.

We now turn our attention to explaining and interpreting a puzzle that has arisen in the empirical investigation of residual income models. We observe the almost universal undervaluation in applications of such models (Dechow et al. (1999), Myers (1999), Choi et al. (2006)). The undervaluation follows a "naive" application of the Ohlson (1995) residual income model to the valuation of equity when accounting is conservative, using as an estimate for price $P_{t}$ the valuation function $V_{t}=b_{t}+\frac{\omega}{R-\omega} x_{t}$, where $\omega$ is the persistence of residual income. ${ }^{14}$ The majority of studies use the reported book equity and residual income as appropriate proxies for the corresponding unbiased values to compute this valuation function and estimate the persistence parameter $\omega$ using an autoregressive model of residual earnings. The use of this valuation equation generates the following expression for the ratio of intrinsic residual income valuation to market price:

$$
\lim _{s \rightarrow \infty} \frac{E_{t}\left[V_{t+s}\right]}{E_{t}\left[P_{t+s}\right]}=\lim _{s \rightarrow \infty} \frac{E_{t}\left[b_{t+s}+\frac{\omega}{R-\omega}\left(\frac{e_{t+s}}{b_{t+s-1}}-(R-1)\right) b_{t+s-1}\right]}{E_{t}\left[P_{t+s}\right]}=\frac{1}{1+\chi}\left(1+\frac{\omega \chi}{(R-\omega)}\left(\frac{R}{1+g}-1\right)\right) .
$$

If we assume $\omega=0.6$ as evidenced in prior literature, and assume plausible parameters $\mathrm{R}=$ 1.12 and $\mathrm{g}=6 \%$ (Dechow et al. (1999), Gregory et al. (2005)), we find that, when book value is two-thirds of market value, corresponding to $\chi=0.5$, the undervaluation is $32 \%$. We also note that most of this undervaluation comes from the relatively low value of book-to-market value. The contribution from the present value of (positive) residual income makes only a small difference, roughly $1 \%$; failing to bridge the gap between book and market values of equity. Even at low degrees of conservatism $(\chi=0.1)$, there is a significant undervaluation of $10 \%$ in residual income valuations.

\footnotetext{
${ }^{14}$ We note that the "other information" variable plays a role of minor adjustment in valuation due to the difficulty of specification in prior empirical studies.
} 
In this case, we estimate that book value is $90 \%$ of the market value and that the residual income reduces the shortfall by less than one percentage point. We illustrate the impact of conservatism on the undervaluation in simple residual income models, the return on equity and the price-earnings ratio in Figure 1. The closeness of the curves labeled 'Book to Market' and 'Valuation to Market' in Figure 1 reinforces the minimal impact of the discounted value of residual income.

\section{<Insert Figure 1 about here>}

Consideration of Figure 1 illustrates the expected result that the price-earnings ratio and the return on equity are inversely related to book-to-market via accounting conservatism. The graph covers the range of values from that of a book value that is twice the market value, corresponding to aggressive accounting with $\chi=-0.5$, to a book value that is just one third of market value corresponding to conservative accounting with $\chi=2.0$. The price earnings ratio increases from 5 to 13 when $\chi$ increases from -0.5 to 2.0 . The corresponding increase in the return on equity is from a value of $9 \%$ when $\chi=-0.5$ to a value of $24 \%$ when $\chi=2.0$. The 'unbiased' PE ratio is 8.8 with a corresponding unbiased return on equity equal to the cost of capital of $12 \%$.

\section{The Supporting Evidence}

We collect relevant data from Compustat from 1976 to 2010. Following conventions, firms with negative book values (Compustat item: CEQ) are deleted. Reported earnings are measured as net income before extraordinary items (IB). The adjusted number of shares outstanding and adjusted dividends, as well as adjusted price of equity three months after the end of the fiscal year, are collected from the Centre for Research in Security Prices (CSRP). ${ }^{15}$ All variables used in our estimation are divided by the adjusted number of shares in issue to reduce heteroscedasticity and increase comparability across time. The price-to-book ratio is measured by the market value of equity and the book value of equity at the end of the year. Observations with a price per share less than $\$ 1$ are

\footnotetext{
${ }^{15}$ Adjusted dividends in merged CRSP and Compustat file are ordinary and return-of-capital dividends, adjusted using the price adjustment factor.
} 
deleted. When we estimate abnormal earnings, we assume a constant cost of capital of $12 \%$ in its computation. ${ }^{16}$ We provide summary statistics in Table 1.

\section{< Insert Table 1 about here>}

Panel A of Table 1 shows that the average price-to-book ratio is about 2.14 and the median is about 1.51 in our sample period. The mean and median of forward earnings yield are $4.8 \%$ and $6.1 \%$ respectively. The mean and median of return on equity are $7.8 \%$ and $10.6 \%$ respectively.

Since valuation weights are not only functions of conservatism measure, $\chi$, but are also associated with the persistence of abnormal earnings, $\omega$, we examine the relation between valuation weights and conservatism based on 25 portfolios, which are formed on five $\chi$ quintiles and five $\omega$ quintiles.

In our modified valuation model, equation (28), the weights attached to book values, earnings and dividends result from the interaction between the persistence of abnormal earnings, and our conservative adjustment. Since our primary concern is to test empirically the validity of our adjustments to the Ohlson model for conservatism, we do this by controlling for the variation in persistence. Our revised formulation as in equation (28) gives rise to the following hypothesis.

Hypothesis: The weights attached to book values and earnings in a regression of market values on book values, earnings and dividends are increasing functions of the degree of conservatism for a given level of persistence of abnormal earnings, while the corresponding weight attached to dividends is a decreasing function of conservatism.

In order to test the hypothesis, we first estimate the valuation weights and the parameters of the information dynamics as a time series following Myers (1999) who suggests that the parameters should reflect firms' economic environment, production technology and accounting policies. To control for the variation in persistence, we carry out a two-way analysis of the data by classifying the

\footnotetext{
${ }^{16}$ Our main results are similar when we use a cost of capital of $9 \%$ and $15 \%$ in our analysis.
} 
data into a 25 portfolios based on quintiles of the persistence of abnormal earnings and of conservatism. Although income in this theoretical model, is supposedly comprehensive income, as in prior literature (for example, Dechow et al. (1999)), ${ }^{17}$ we test the model by using reported earnings as a proxy of comprehensive earnings. The persistence parameter $(\omega)$ is calculated using equation (1) for all firms with at least 10 observations, while consistent with the theory developed in equation (33) the long run price-to-book, $\sum p_{t} / \sum b_{t}$ is used as the measure conservatism $\chi$ (Bernard and Durlauf (1996)). ${ }^{18}$ After deleting sample firms with persistence $(\omega)$ out of range $(0,1)$, the final sample statistics are presented in Panel B of Table 1. The data set consists of 4,525 firms and 67,251 observations available over the period 1976-2010. The coefficients of book value, earnings and dividends are estimated for each of the 25 portfolios by regressing price on book value, reported earnings and dividends.

\section{< Insert Table 2 about here>}

In Table 2, we show the results of this two-way classification. We notice that within the same persistence quintile, the coefficients of book value are monotonically increasing in the quintiles of conservatism. In the case of reported earnings, strict monotonicity is observed in the second and third quintiles while there are only minor violations to monotonicity in the remaining quintiles ${ }^{19}$. For the coefficients of book value and earnings, we observe strict monotonicity in conservatism in their averages.

However turning to dividends, we find very little evidence of monotonicity, except perhaps

\footnotetext{
${ }^{17}$ This may violate the clean surplus accounting assumption. However it eliminates potentially confounding effects of one-time items. We use reported earnings as a proxy, not only because dirty surplus accounting is not a first order concern, but empirical evidence also shows that the residual income valuation model is robust to dirty surplus earnings (Isidro et al. (2006) and Heinrichs et al. (2013)).

${ }^{18}$ The results (not reported here) are very similar when we use mean P/B or median P/B as the measure of conservatism. Note that there is no commonly accepted measure of accounting conservatism. For example, with respect to the recently developed C-score in Khan and Watts (2009), Ashton and Wang (2013) argue that C-score 'is really a measure of propensity to follow a conservative accounting policy.'

${ }^{19}$ Our results appear to contradict those of Chen et al. (2014). Although they agree that pricing multiples are affected by both persistence of earnings and conservatism, with conservative firms having a greater degree of persistence in earning, they do not model and test the interaction between the persistence of earnings and conservatism. A glance at Table 2 shows that persistence plays a greater role in determing the earnings weights than conservatism.
} 
in the average values of dividends. Even here strict monotonicity is observed only in the case of the average value of the conservatism parameter. Of more concern is that the theory of Ohlson (1995) predicts negative values for this coefficient and our adjustments do not change the predicted sign. This puzzle of the positive sign of dividends in residual income valuation models is well documented in the literature and remains unresolved (Rees (1997), Hand and Landsman (2005)). It would appear to be a problem intrinsic to the formulation of the Ohlson (1995) model, rather than a problem attributable to our modification of the model for conservatism. ${ }^{20}$

Our two-way classification lends itself to further testing of the Ohlson (1995) model and a more rigorous test of our adjustments for conservatism to the model. Table 3 reports the median values of the quintile classification of conservatism $\chi\left(q_{i}\right)$ and persistence $\omega\left(q_{i}\right)$ where $q_{i}$ denotes the $i$ th quintile. We can construct theoretical values of the coefficients of book values and earnings based on these quintile medians to give the theoretical values of the averages. The theoretical average values of the coefficients of the $j$ th book value quintile, $\bar{\chi}\left(q_{j}\right)$, are computed from the formula:

$$
\frac{1}{5} \sum \frac{R\left[1-\omega\left(q_{i}\right)\right]}{R-\omega\left(q_{i}\right)}\left[1+\chi\left(q_{j}\right)\right],
$$

by summing over $i$, with the corresponding average values $\bar{\omega}\left(q_{i}\right)$ for the persistence parameter obtained by summing over $j$, where $\omega\left(q_{i}\right), \chi\left(q_{j}\right)$ are median values of the $i$ th and $j$ th quintile of persistence and conservatism respectively. Similarly the $i$ th and $j$ th quintiles of the average coefficients for earnings are obtained from the formula:

$$
\frac{1}{5} \sum \frac{R \omega\left(q_{i}\right)}{R-\omega\left(q_{i}\right)}\left[1+\chi\left(q_{j}\right)\right]
$$

These theoretical averages are shown in Table 3 and Figure 2 compares the theoretical values with the corresponding observed values. If we consider only the slopes or trends, we see that both in the case of persistence and of conservatism reasonable agreement between theory and

\footnotetext{
${ }^{20}$ Although Lo and Lys (2000) argue that size or scale differences across firms may explain the observed 'anomalous' valuation of dividends for a sample of US firms, scaling variables in the Ohlson (1995) model by lagged market values does not solve the puzzled sign on dividends for European markets (Goncharov and Veenman (2014)).
} 
observed occurs. This observation of the trend is supported by a consideration of the coefficient of correlation between theory and observed values. The correlations between the theoretical ${ }^{21}$ and observed values in the case of the $\chi$-quintiles is in excess of 0.89 for both book values and earnings, suggesting that our adjustments for conservatism are substantially correct. It is somewhat lower in the case of the persistence measure, the $\omega$-quintiles, with the correlation between the theoretical and observed values being 0.58 for reported earnings. However the observed coefficient of, or weight attached, to book values is lower than theory predicts; a result first observed and discussed by Dechow et al. (1999). However Dechow et al. (1999) report that the unadjusted Ohlson (1995) model results in a theoretical value 3 times that observed. In our adjusted model the theoretical value is just 1.22 times the observed value. The average value for reported earnings across all quintiles is 2.13 compared with a theoretical average of 2.17.

$$
\begin{aligned}
& \text { < Insert Table } 3 \text { about here> } \\
& \text { < Insert Figure } 2 \text { about here> }
\end{aligned}
$$

\section{Conclusion}

In this paper, we establish a formal relationship between the unbiased and unobservable accounting system posited by Ohlson (1995) and reported systems distorted by the principle of conservatism. We develop a methodology based on stochastic difference equations to analyse several apparently distinct forms of conservatism: the unconditional conservatism of accelerated depreciation combined with historical cost accounting in an inflationary environment, plus the conditional conservatism associated with income recognition and income smoothing. We find that all these specific examples assume a common analytical structure for the relationship between prices, book values, earnings and dividends. We establish the generality of these findings and argue that within a valuation framework unconditional and conditional conservatism are indistinguishable in their

\footnotetext{
${ }^{21}$ In this exercise we set the cost of capital at $12 \%, R=1.12$. However, we find that the value of $R$ is not crucial and results based on costs of capital of $9 \%$ and $15 \%$ are very similar.
} 
impact. Our generalisation enables us to identify a summary theoretical measure of conservatism, which we are able to equate to the long-run ratio of price-to-book. Our theoretical analysis also offers an explanation of the hitherto anomalous result in the empirical literature of undervaluation in simple residual income valuation models and the failure to detect conservatism in the linear information dynamics. Our empirical evidence accords well with the theory developed.

The importance of this study carries messages for practitioners and academics. The first of these is that while it may be convenient in the academic literature and professional literature to talk about conditional and unconditional conservatism as different phenomena, they have the same common origin of a desire to be cautious in the recognition of increases in economic wealth. Hence the two manifest themselves in the statements of the financial positon in the same way, with reported book values lagging prices. This view that conservatism is essentially a timing issue is also echoed in the recent P D Leake ICAEW Lecture (Barker 2014) in which he argues that such a definition is general and no distinction is made between the different sources of conservatism.

Secondly, our revised valuation model is effectively a theoretical cross sectional asset pricing model, using reported data. The implication of our analysis is that the coefficients in such cross-sectional regressions depend on both the degree of accounting conservatism and the persistence of abnormal earnings. Thus any grouping that explores empirically or employs such coefficients needs to ensure homogeneity in these two aspects, whether an industry classification, as typically adopted in this literature, is sufficient is a moot point. This observation may offer a partial explanation of the relatively 'noisy' results that emerge in such empirical investigations to determine the cost of equity capital and their abandonment in favour of residual income models of the sort discussed in this paper. 


\section{REFERENCES}

Ahmed, S.T., R.M. Morton and T.F. Schaefer (2000), 'Accounting Conservatism and Valuation of Accounting Numbers: Evidence on the Feltham and Ohlson (1996) Model', Journal of Accounting, Auditing and Finance, Vol.15, pp.271-292.

Amir, E. and B. Lev (1996) 'Valuation-Relevance of Non-Financial Information: the Wireless Communications Industry', Journal of Accounting and Economics, Vol. 22, pp.3-30.

Ashton, D., K. Peasnell and P. Wang (2011), 'Residual Income Valuation Models and Inflation', European Accounting Review, Vol. 20, No.3, pp.459-483.

Ashton, D. and P. Wang (2013), 'Valuation weights, linear dynamics and accounting conservatism: an empirical analysis', Journal of Business Finance and Accounting, Vol.40, No.1-2, pp.1-25.

Ball, R. and L. Shivakumar (2005), 'Earnings Quality in U.K. Private Firms', Journal of Accounting and Economics, Vol.39, pp.83-128.

Barth, M., W. Beaver and W. Landsman (1998), 'Relative Valuation Roles of Equity Book Value and Net Income as a Function of Financial Health', Journal of Accounting and Economics, Vol.25, pp.1-34.

Barker, R (2014), 'Is IFRS Conservative’ P D Leake Lecture ICAEW, October 2014.

Basu, S. (1997), 'The Conservatism Principle and the Asymmetric Timeliness of Earnings', Journal of Accounting and Economics, Vol.24, pp.3-37.

Beaver, W. and S. Ryan (2000), 'Biases and Lags in Book Value and Their Effects on the Ability of the Book-to-Market Ratio to Predict Book Return on Equity', Journal of Accounting Research, Vol.38, pp.127-148.

Beaver, W. and S. Ryan (2005), 'Conditional and Unconditional Conservatism: Concepts and Modeling', Review of Accounting Studies, Vol.10, pp.269-309.

Bernard, A. B. and S. N. Durlauf (1996), 'Interpreting Tests of Convergence', Journal of Econometrics, Vol.71, pp.161-173.

Chen, L., D. Folsom, W. Paek and H. Sami, (2014), 'Accounting Conservatism, Earnings Persistence, 
and Pricing Multiples on Earnings', Accounting Horizons, Vol. 28, pp. 233-260.

Choi, Y-S, J. O'Hanlon and P. Pope (2006), 'Conservative Accounting and Linear Information Valuation Models', Contemporary Accounting Research, Vol.23, pp.73-101.

Collins, D., M. Pincus and H. Xie (1999), 'Equity Valuation and Negative Earnings: the Role of Book Value of Equity', The Accounting Review, Vol.74, pp.29-61.

Dechow, P.M., A.P. Hutton and R.G. Sloan (1999), 'An Empirical Assessment of the Residual Income Valuation Model', Journal of Accounting and Economics, Vol.26, pp.1-34.

Feltham, G. and J. Ohlson (1995), 'Valuation and Clean Surplus Accounting for Operating and Financial Activities', Contemporary Accounting Research, Vol.11, pp.689-732.

Feltham G. and J. Ohlson (1996), 'Uncertainty Resolution and the Theory of Depreciation Measurement', Journal of Accounting Research, Vol.34, pp.209-234.

Fisher F. M. and J. McGowan (1983), 'On the misuse of Accounting Rates of Return to infer Monopoly Profits', American Economic Review, Vol.73, No.1, pp.82-97.

Francis, J. and K. Schipper (1999), 'Have Financial Statements Lost Their Valuation Relevance?' Journal of Accounting Research, Vol.37, pp.319-352.

Garcia Lara, J.M., B.G. Osma and F. Penalva (2011), 'Conditional Conservatism and Cost of Capital', Review of Accounting Studies, Vol.16(2):247-271.

Givoly, D., C. Hayn and A. Natarajan (2007), 'Measuring Reporting Conservatism', The Accounting Review, Vol.82, pp.65-106.

Goncharov, I. and D. Veenman (2014), 'Stale and Scale Effects in Markets-Based Accounting Research: Evidence from the Valuation of Dividends', The European Accounting Review 23 (1), pp. 25-55.

Gregory, A., W. Saleh and J. Tucker (2005), 'A UK Test of an Inflation-Adjusted Ohlson Model', Journal of Business Finance \& Accounting, Vol.32, No. 3-4, pp.487-534.

Hand, J. and W. Landsman (2005), 'The Pricing of Dividends in Equity Valuation', Journal of Business Finance and Accounting, Vol.32, pp.435-469. 
Heinrichs, N., D. Hess, C. Homburg, M. Lorenz and S. Sievers (2013), 'Extended Dividend, Cash

Flow and Residual Income Valuation Models - Accounting for Deviations from Ideal Conditions', Contemporary Accounting Research 30 (1), pp. 42-79.

Hughes, J., J. Li and M. Zhang (2004), 'Valuation and Accounting for Inflation and Foreign Exchange', Journal of Accounting Research, Vol.42, pp.731-754.

Isidro, H., J. O’Hanlon and S. Young (2006), 'Dirty Surplus Accounting Flows and Valuation Errors', Abacus 42 (3-4), pp. 302-344.

Khan M. and R. Watts (2009), 'Estimation and Empirical Properties of a Firm-Year Measure of Accounting Conservatism', Journal of Accounting and Economics, Vol.48, pp.132-150.

Lintner, J. (1956), 'Distribution of Incomes of Corporations among Dividends, Retained Earnings, and Taxes,' American Economic Review, Vol. 46, pp.97-113.

Lo, K. and T. Lys (2000), 'The Ohlson Model: Contribution to Valuation Theory, Limitations, and Empirical Applications', Journal of Accounting, Auditing and Finance, 15 (3), pp. 337-367.

Miller, M., and F. Modigliani (1961), 'Dividend Policy, Growth and the Valuation of Shares', Journal of Business Vol.34, pp.411-433.

Modigliani, F. and M. Miller (1958), 'The Expected Cost of Equity Capital, Corporation Finance, and the Theory of Investment', American Economic Review, Vol.48, pp. 261-297.

Myers, J. (1999), 'Implementing Residual Income Valuation with Linear Information Dynamics', The Accounting Review, Vol.74, pp.1-28.

Ohlson, J. (1995), 'Earnings, Book Values, and Dividends in Security Valuation', Contemporary Accounting Research, Vol.11, pp.661-687.

Ohlson J. and Z. Gao (2006), 'Earnings Growth and Value', Foundations and Trends in Accounting, Vol.1, pp.1-70.

Pae, J., D. Thornton and M. Welker (2005), 'The Link Between Earnings Conservatism and Balance Sheet Conservatism', Contemporary Accounting Research, Vol.22, pp.693-717.

Penman, S. (1996), 'The Articulation of Price-Earnings Ratios and Market-to-Book Ratios and 
Evaluation of Growth', Journal of Accounting Research, Vol.34, pp.235-260.

Penman, S. (1998), 'Combining Earnings and Book Value in Equity Valuation', Contemporary Accounting Research, Vol.15, pp.291-324.

Pope, P. and M. Walker (1999), 'International Differences in Timeliness, Conservatism and Classification of Earnings', Journal of Accounting Research, Vol.37, pp.53-87.

Rajan, M.V., S. Reichelstein and M.T. Soliman (2007), 'Conservatism, Growth and Return on Investment', Review of Accounting Studies, Vol.12, pp.325-370.

Rees W. P. (1997), ‘The Impact of Dividends, Debt and Investment on Valuation Models', Journal of Business Finance \& Accounting, Vol.24, No.7-8, pp.1111-1140.

Watts, R. (2003), 'Conservatism in Accounting Part I: Explanations and Implications', Accounting Horizons, Vol.17, pp.207-221.

Yee, K. (2005), ‘Aggregation, Dividend Irrelevancy, and Earnings-Value Relations', Contemporary Accounting Research, Vol. 22 (2), pp.453-480.Zhang, X-J. (2000), 'Conservative Accounting and Equity Valuation', Journal of Accounting and Economics, Vol.29, pp.125-148. 


\section{APPENDIX A}

\section{Proofs of equations (5)-(8):}

Since $b_{t}^{\prime}-\left(1-\alpha^{\prime}\right) b_{t-1}^{\prime}=b_{t}-(1-\alpha) b_{t-1}=I_{t}$ holds for all $\mathrm{t}$, we have

$$
b_{t}-(1-\alpha)^{t} b_{0}=\sum_{s=1}^{s=t} I_{s}(1-\alpha)^{t-s} \text {. }
$$

Assume $I_{t}=(1+g) I_{t-1}+u_{t}$ and $E\left[u_{t}\right]=0$. Taking expectations on both sides, we have

$$
\begin{aligned}
E\left[b_{t}\right] & =(1-\alpha)^{t} b_{0}+\sum_{s=1}^{s=t} I_{0}(1+g)^{s}(1-\alpha)^{t-s} \\
& =(1-\alpha)^{t} b_{0}+\frac{(1+g)^{t+1}}{g+\alpha}\left[1-\left(\frac{1-\alpha}{1+g}\right)^{t}\right] I_{0} .
\end{aligned}
$$

Similarly, we have

$$
E\left[b_{t}^{\prime}\right]=\left(1-\alpha^{\prime}\right)^{t} b_{0}+\frac{(1+g)^{t+1}}{g+\alpha^{\prime}}\left[1-\left(\frac{1-\alpha^{\prime}}{1+g}\right)^{t}\right] I_{0}
$$

Hence, we have

$$
\frac{E\left[b_{t}^{\prime}\right]}{E\left[b_{t}\right]}=\frac{\left(1-\alpha^{\prime}\right)^{t} b_{0}+\frac{(1+g)^{t+1}}{g+\alpha^{\prime}}\left[1-\left(\frac{1-\alpha^{\prime}}{1+g}\right)^{t}\right] I_{0}}{(1-\alpha)^{t} b_{0}+\frac{(1+g)^{t+1}}{g+\alpha}\left[1-\left(\frac{1-\alpha}{1+g}\right)^{t}\right] I_{0}}=\frac{\left(\frac{b_{0}}{1+g}-\frac{I_{0}}{g+\alpha^{\prime}}\right)\left(\frac{1-\alpha^{\prime}}{1+g}\right)^{t}+\frac{1}{g+\alpha^{\prime}}}{\left(\frac{b_{0}}{1+g}-\frac{I_{0}}{g+\alpha}\right)\left(\frac{1-\alpha}{1+g}\right)^{t}+\frac{1}{g+\alpha}}
$$

For a relatively large $t$, as in general empirical investigations dealing with established firms, and with $0<\alpha \leq 1$, the terms $\left(\frac{1-\alpha^{\prime}}{1+g}\right)^{t} \sim 0$ and $\left(\frac{1-\alpha}{1+g}\right)^{t} \sim 0$, we have

$$
E\left[b_{t}^{\prime} \mid \Lambda_{t}\right]=\frac{g+\alpha}{g+\alpha^{\prime}} b_{t}=\left(1+\frac{\alpha-\alpha^{\prime}}{g+\alpha^{\prime}}\right) b_{t}
$$

Since $e_{t}^{\prime}+\alpha^{\prime} b_{t-1}^{\prime}=e_{t}+\alpha b_{t-1}=Y_{t}$,

$$
\begin{gathered}
E\left[e_{t}^{\prime} \mid \Lambda_{t}\right]=e_{t}+E\left[b_{t}^{\prime}-b_{t-1}^{\prime} \mid \Lambda_{t}\right]-\left(b_{t}-b_{t-1}\right)=e_{t}+\frac{(g+\alpha)}{\left(g+\alpha^{\prime}\right)}\left(b_{t}-b_{t-1}\right)-\left(b_{t}-b_{t-1}\right), \text { or } \\
E\left[e_{t}^{\prime} \mid \Lambda_{t}\right]=e_{t}+\frac{\left(\alpha-\alpha^{\prime}\right)}{\left(g+\alpha^{\prime}\right)}\left(b_{t}-b_{t-1}\right) .
\end{gathered}
$$


Equation (6) and CSR imply that $E\left[e_{t}^{\prime} \mid \Lambda_{t}\right]=e_{t}+\frac{\alpha-\alpha^{\prime}}{\alpha^{\prime}+g}\left(e_{t}-d_{t}\right)=\frac{\alpha+g}{\alpha^{\prime}+g} e_{t}-\frac{\alpha-\alpha^{\prime}}{\alpha^{\prime}+g} d_{t}$.

Hence the valuation equation (2) becomes

$$
\begin{aligned}
E\left[V_{t} \mid \Lambda_{t}\right]=\left(1-\frac{\omega(R-1)}{R-\omega}\right) E\left[b_{t}^{\prime} \mid \Lambda_{t}\right]+\frac{\omega(R-1)}{R-\omega} \frac{R}{R-1} E\left[e_{t}^{\prime} \mid \Lambda_{t}\right]-\frac{\omega(R-1)}{R-\omega} d_{t} \\
=\left(1-\frac{\omega(R-1)}{R-\omega}\right)\left(1+\frac{\alpha-\alpha^{\prime}}{\alpha^{\prime}+g}\right) b_{t}+\frac{\omega(R-1)}{R-\omega} \frac{R}{R-1}\left(1+\frac{\alpha-\alpha^{\prime}}{\alpha^{\prime}+g}\right) e_{t} \\
-\frac{\omega(R-1)}{R-\omega} \frac{R}{R-1} \frac{\alpha-\alpha^{\prime}}{\alpha^{\prime}+g} d_{t}-\frac{\omega(R-1)}{R-\omega} d_{t}
\end{aligned}
$$

or

$$
E\left[V_{t} \mid \Lambda_{t}\right]=\frac{R(1-\omega)}{R-\omega}\left(1+\frac{\alpha-\alpha^{\prime}}{\alpha^{\prime}+g}\right) b_{t}+\frac{R \omega}{R-\omega}\left(1+\frac{\alpha-\alpha^{\prime}}{\alpha^{\prime}+g}\right) e_{t}-\left(\frac{(R-1) \omega}{R-\omega}+\frac{R \omega}{R-\omega} \frac{\alpha-\alpha^{\prime}}{\alpha^{\prime}+g}\right) d_{t}
$$

or

$$
E\left[V_{t} \mid \Lambda_{t}\right]=\frac{R(1-\omega)}{R-\omega}\left(1+\chi_{U}\right) b_{t}+\frac{R \omega}{R-\omega}\left(1+\chi_{U}\right) e_{t}-\left(\frac{(R-1) \omega+R \omega \chi_{U}}{R-\omega}\right) d_{t}
$$

where $\chi_{U}=\frac{\alpha-\alpha^{\prime}}{\alpha^{\prime}+g}$.

Proofs of equations (18) and (19):

Since $e_{t}=e_{t}^{\prime}+\Phi_{t}-\varepsilon_{t}$, where $\varepsilon_{t}=\varepsilon b_{t-1}$, and

$$
\Phi_{t}=\left\{\begin{array}{l}
\delta_{t}^{\prime}=\lambda^{\prime} \varepsilon_{t}+\left(1-\lambda^{\prime}\right) \delta_{t-1}^{\prime} \text { if } \varepsilon<0 \\
\delta_{t}=\lambda \varepsilon_{t}+(1-\lambda) \delta_{t-1} \text { if } \varepsilon \geq 0
\end{array}\right.
$$

$\lambda, \lambda^{\prime} \in[0,1]$, for a large $\mathrm{t}, \delta_{t}, \delta_{t}^{\prime}$ can be modeled by:

$$
\delta_{t}=\lambda \sum_{s=0}^{t-1}(1-\lambda)^{s} \varepsilon_{t-s}, \delta_{t}^{\prime}=\lambda^{\prime} \sum_{s=0}^{t-1}\left(1-\lambda^{\prime}\right)^{s} \varepsilon_{t-s}
$$

We have:

$$
\begin{gathered}
E\left[\varepsilon_{t}-\Phi_{t}\right]=E\left[\left(\varepsilon_{t}-\left(\lambda \varepsilon_{t}+(1-\lambda) \delta_{t-1}\right)\right) \mid \varepsilon \geq 0\right]+E\left[\left(\varepsilon_{t}-\left(\lambda^{\prime} \varepsilon_{t}+\left(1-\lambda^{\prime}\right) \delta_{t-1}^{\prime}\right)\right) \mid \varepsilon<0\right] \\
=(1-\lambda) E\left[\left(\varepsilon_{t}-\delta_{t-1}\right) \mid \varepsilon \geq 0\right]+\left(1-\lambda^{\prime}\right) E\left[\left(\varepsilon_{t}-\delta_{t-1}^{\prime}\right) \mid \varepsilon<0\right]
\end{gathered}
$$




$$
\begin{aligned}
& =(1-\lambda) E\left[\left(\varepsilon_{t}-\lambda \sum_{s=0}^{t-2}(1-\lambda)^{s} \varepsilon_{t-s-1}\right) \mid \varepsilon \geq 0\right]+\left(1-\lambda^{\prime}\right) E\left[\left(\varepsilon_{t}-\lambda^{\prime} \sum_{s=0}^{t-2}\left(1-\lambda^{\prime}\right)^{s} \varepsilon_{t-s-1}\right) \mid \varepsilon<0\right] \\
& =(1-\lambda) E\left[\left(\varepsilon b_{t-1}-\lambda \sum_{s=1}^{t-1}(1-\lambda)^{s-1} \varepsilon b_{t-s-1}\right) \mid \varepsilon \geq 0\right]+\left(1-\lambda^{\prime}\right) E\left[\left(\varepsilon b_{t-1}-\lambda^{\prime} \sum_{s=1}^{t-1}\left(1-\lambda^{\prime}\right)^{s-1} \varepsilon b_{t-s-1}\right) \mid \varepsilon<0\right] \\
& =(1-\lambda) E[\varepsilon \mid \varepsilon \geq 0] E\left[\left(b_{t-1}-\lambda \sum_{s=1}^{t-1}(1-\lambda)^{s-1} b_{t-s-1}\right)\right]+\left(1-\lambda^{\prime}\right) E[\varepsilon \mid \varepsilon<0] E\left[\left(b_{t-1}-\lambda^{\prime} \sum_{s=1}^{t-1}\left(1-\lambda^{\prime}\right)^{s-1} b_{t-s-1}\right)\right] \\
& =\kappa(1-\lambda) E\left[\sum_{s=1}^{t-1}(1-\lambda)^{s-1}\left(b_{t-s}-b_{t-s-1}\right)\right]+(1-\kappa)\left(1-\lambda^{\prime}\right) E\left[\sum_{s=1}^{t-1}\left(1-\lambda^{\prime}\right)^{s-1}\left(b_{t-s}-b_{t-s-1}\right)\right],
\end{aligned}
$$

where $\kappa=E[\varepsilon \mid \varepsilon>0]$.

Assume that the expected changes in book values have a growth rate of $\mathrm{g}$.

$$
\begin{aligned}
& E\left[b_{t}-b_{t-1}\right]=(1+g)^{s} E\left[b_{t-s}-b_{t-s-1}\right], s=0,1,2 \ldots \ldots \text { and we have: } \\
& \begin{aligned}
E\left[\left(\varepsilon_{t}-\Phi_{t}\right) \mid \Lambda_{t}\right] & =\kappa(1-\lambda) E\left[\sum_{s=1}^{t-1}(1-\lambda)^{s-1}(1+g)^{-s}\left(b_{t}-b_{t-1}\right)\right] \\
& +(1-\kappa)\left(1-\lambda^{\prime}\right) E\left[\sum_{s=1}^{t-1}\left(1-\lambda^{\prime}\right)^{s-1}(1+g)^{-s}\left(b_{t}-b_{t-1}\right)\right] \\
& =\frac{\kappa(1-\lambda)}{g+\lambda}\left(b_{t}-b_{t-1}\right)+\frac{(1-\kappa)\left(1-\lambda^{\prime}\right)}{g+\lambda^{\prime}}\left(b_{t}-b_{t-1}\right)=\left[\frac{\kappa(1-\lambda)}{g+\lambda}+\frac{(1-\kappa)\left(1-\lambda^{\prime}\right)}{g+\lambda^{\prime}}\right]\left(b_{t}-b_{t-1}\right)
\end{aligned}
\end{aligned}
$$

$E\left[e_{t}^{\prime} \mid \Lambda_{t}\right]=e_{t}+E\left[\left(\varepsilon_{t}-\Phi_{t}\right) \mid \Lambda_{t}\right]$, or

$$
E\left[e_{t}^{\prime} \mid \Lambda_{t}\right]=e_{t}+\left(\frac{\kappa(1-\lambda)}{g+\lambda}+\frac{(1-\kappa)\left(1-\lambda^{\prime}\right)}{g+\lambda^{\prime}}\right)\left(b_{t}-b_{t-1}\right)
$$

CSR implies: $E\left[e_{t}^{\prime}-\left(b_{t}^{\prime}-b_{t-1}^{\prime}\right) \mid \Lambda_{t}\right]=d_{t}=e_{t}-\left(b_{t}-b_{t-1}\right)$

$$
\begin{aligned}
& e_{t}+\left(\frac{\kappa(1-\lambda)}{g+\lambda}+\frac{(1-\kappa)\left(1-\lambda^{\prime}\right)}{g+\lambda^{\prime}}\right)\left(b_{t}-b_{t-1}\right)-E\left[\left(b_{t}^{\prime}-b_{t-1}^{\prime}\right) \mid \Lambda_{t}\right]=e_{t}-\left(b_{t}-b_{t-1}\right) \\
& E\left[\left(b_{t}^{\prime}-b_{t-1}^{\prime}\right) \mid \Lambda_{t}\right]=\left(1+\frac{\kappa(1-\lambda)}{g+\lambda}+\frac{(1-\kappa)\left(1-\lambda^{\prime}\right)}{g+\lambda^{\prime}}\right)\left(b_{t}-b_{t-1}\right)
\end{aligned}
$$

Under the assumption that long-run growth is positive ensuring that $b_{0}, b_{0}^{\prime}$ are insignificant compared with $b_{t}, b_{t}^{\prime}$, we have:

$$
E\left[b_{t}^{\prime} \mid \Lambda_{t}\right]=\left(1+\frac{\kappa(1-\lambda)}{g+\lambda}+\frac{(1-\kappa)\left(1-\lambda^{\prime}\right)}{g+\lambda^{\prime}}\right) b_{t} .
$$

Therefore, 


$$
\chi_{C}=\frac{\kappa(1-\lambda)}{g+\lambda}+\frac{(1-\kappa)\left(1-\lambda^{\prime}\right)}{g+\lambda^{\prime}}=\frac{1}{g+\lambda^{\prime}}\left[\left(1-\lambda^{\prime}\right)+\kappa \frac{(1+g)}{(g+\lambda)}\left(\lambda^{\prime}-\lambda\right)\right]
$$

\section{Proof of equation (32):}

Since $E\left[V_{t} \mid \Lambda_{t}\right]=\frac{R(1-\omega)}{R-\omega}(1+\chi) b_{t}+\frac{R \omega}{R-\omega}(1+\chi) e_{t}-\left(\frac{(R-1) \omega+R \omega \chi}{R-\omega}\right) d_{t}$,

no-arbitrage condition $R E\left[V_{t} \mid \Lambda_{t}\right]=E\left[V_{t+1}+d_{t+1} \mid \Lambda_{t}\right]$ implies that

$$
\begin{aligned}
& R\left\{\frac{R(1-\omega)}{R-\omega}(1+\chi) b_{t}+\frac{R \omega}{R-\omega}(1+\chi) e_{t}-\left(\frac{(R-1) \omega+R \omega \chi}{R-\omega}\right) d_{t}\right\} \\
& =E\left\{\frac{R(1-\omega)}{R-\omega}(1+\chi) b_{t+1}+\frac{R \omega}{R-\omega}(1+\chi) e_{t+1}+\left(1-\frac{(R-1) \omega+R \omega \chi}{R-\omega}\right) d_{t+1}\right\}
\end{aligned}
$$

Note that $x_{t}=e_{t}-(R-1) b_{t-1}$. The above can be written as

$$
\begin{aligned}
& R\left\{\frac{R(1-\omega)}{R-\omega}(1+\chi) b_{t}+\frac{R \omega}{R-\omega}(1+\chi)\left(x_{t}+(R-1) b_{t-1}\right)-\left(\frac{(R-1) \omega+R \omega \chi}{R-\omega}\right) d_{t}\right\} \\
& =E\left\{\frac{R(1-\omega)}{R-\omega}(1+\chi) b_{t+1}+\frac{R \omega}{R-\omega}(1+\chi)\left(x_{t+1}+(R-1) b_{t}\right)+\left(\frac{R-R \omega(1+\chi)}{R-\omega}\right) d_{t+1}\right\} .
\end{aligned}
$$

Applying the clean surplus relation: $b_{t}+d_{t}=R b_{t-1}+x_{t}$, we have

$$
\begin{aligned}
& E\left\{\frac{R(1-\omega)}{R-\omega}(1+\chi) b_{t+1}+\frac{R \omega}{R-\omega}(1+\chi)\left(x_{t+1}+(R-1) b_{t}\right)+\left(\frac{R-R \omega(1+\chi)}{R-\omega}\right)\left(R b_{t}+x_{t+1}-b_{t+1}\right)\right\}= \\
& R\left\{\frac{R(1-\omega)}{R-\omega}(1+\chi) b_{t}+\frac{R \omega}{R-\omega}(1+\chi)\left(x_{t}+(R-1) b_{t-1}\right)-\left(\frac{-\omega+R \omega(1+\chi)}{R-\omega}\right)\left(R b_{t-1}+x_{t}-b_{t}\right)\right\},
\end{aligned}
$$

or

$$
\begin{aligned}
& \frac{R}{R-\omega} E\left[x_{t+1}\right]=R \frac{\omega}{R-\omega} x_{t}+\frac{R(1-\omega)(1+\chi)-R+R \omega(1+\chi)}{R-\omega} E\left[\left(R b_{t}-b_{t+1}\right)\right] \\
& +\frac{R(R-1) \omega(1+\chi)+R \omega-R^{2} \omega(1+\chi)}{R-\omega}\left(R b_{t-1}-b_{t}\right)
\end{aligned}
$$

i.e.

$$
E\left[x_{t+1}\right]=\omega_{1} x_{t}+\chi\left[\left(R b_{t}-b_{t+1}\right)-\omega_{1}\left(R b_{t-1}-b_{t}\right)\right]+\varepsilon_{x, t+1},
$$

where $\omega_{1}=\omega$. 


\section{APPENDIX B. Accounting Conservatism and Smoothing of Earnings}

Assuming that expected earnings are positive, we can think of a proportion $\rho(\leq 1)$ of earnings being recognised at time t, with a further proportion $\rho(1-\rho)$ being incorporated into time t-1 earnings and so on. We thus model conservatism in the form of the delayed recognition of total earnings. Our model becomes

$$
e_{t}=\sum_{s=0}^{s=\infty} \rho(1-\rho)^{s} e_{t-s}^{\prime}
$$

Assume that there is a long-run average growth in changes for unbiased earnings:

$$
e_{\tau}^{\prime}-e_{\tau-1}^{\prime}=(1+g)\left(e_{\tau-1}^{\prime}-e_{\tau-2}^{\prime}\right)+v_{\tau}
$$

where $v_{\tau}$ is an error term with mean zero and is serially independent. Asymptotically we have

$$
E\left[\left(e_{t}^{\prime}-e_{t}\right) \mid \Lambda_{t}\right]=\frac{1-\rho}{\rho+g} E\left[\left(e_{t}^{\prime}-e_{t-1}^{\prime}\right) \mid \Lambda_{t}\right]
$$

Note that in an unbiased system, the long-run value of $e_{t}^{\prime}=(R-1) b_{t-1}^{\prime}$. Hence

$$
E\left[\left(e_{t}^{\prime}-e_{t}\right) \mid \Lambda_{t}\right]=\frac{1-\rho}{\rho+g} \frac{R-1}{1+g} E\left[\left(b_{t}^{\prime}-b_{t-1}^{\prime}\right) \mid \Lambda_{t}\right]
$$

Given the clean surplus relationship $b_{t}^{\prime}-b_{t-1}^{\prime}=b_{t}-b_{t-1}+e_{t}^{\prime}-e_{t}$, it follows from equation (B.2) that

$$
E\left[\left(b_{t}^{\prime}-b_{t-1}^{\prime}\right) \mid \Lambda_{t}\right]=\frac{(\rho+g)(1+g)}{(\rho+g)(1+g)-(R-1)(1-\rho)}\left(b_{t}-b_{t-1}\right)
$$

Under the assumption that long-run growth is positive ensuring that $b_{0}, b_{0}^{\prime}$ are insignificant compared with $b_{t}, b_{t}^{\prime}$, we have:

$$
E\left[b_{t}^{\prime} \mid \Lambda_{t}\right]=\left[1+\frac{(R-1)(1-\rho)}{(\rho+g)(1+g)-(R-1)(1-\rho)}\right] b_{t} .
$$

(B.2) further implies that

$$
E\left[e_{t}^{\prime} \mid \Lambda_{t}\right]=e_{t}+\chi\left(b_{t}-b_{t-1}\right)
$$

where $\chi=\frac{(R-1)(1-\rho)}{(\rho+g)(1+g)-(R-1)(1-\rho)}$. 
Figure 1: Residual Income Valuation, Accounting Fundamentals and Conservatism

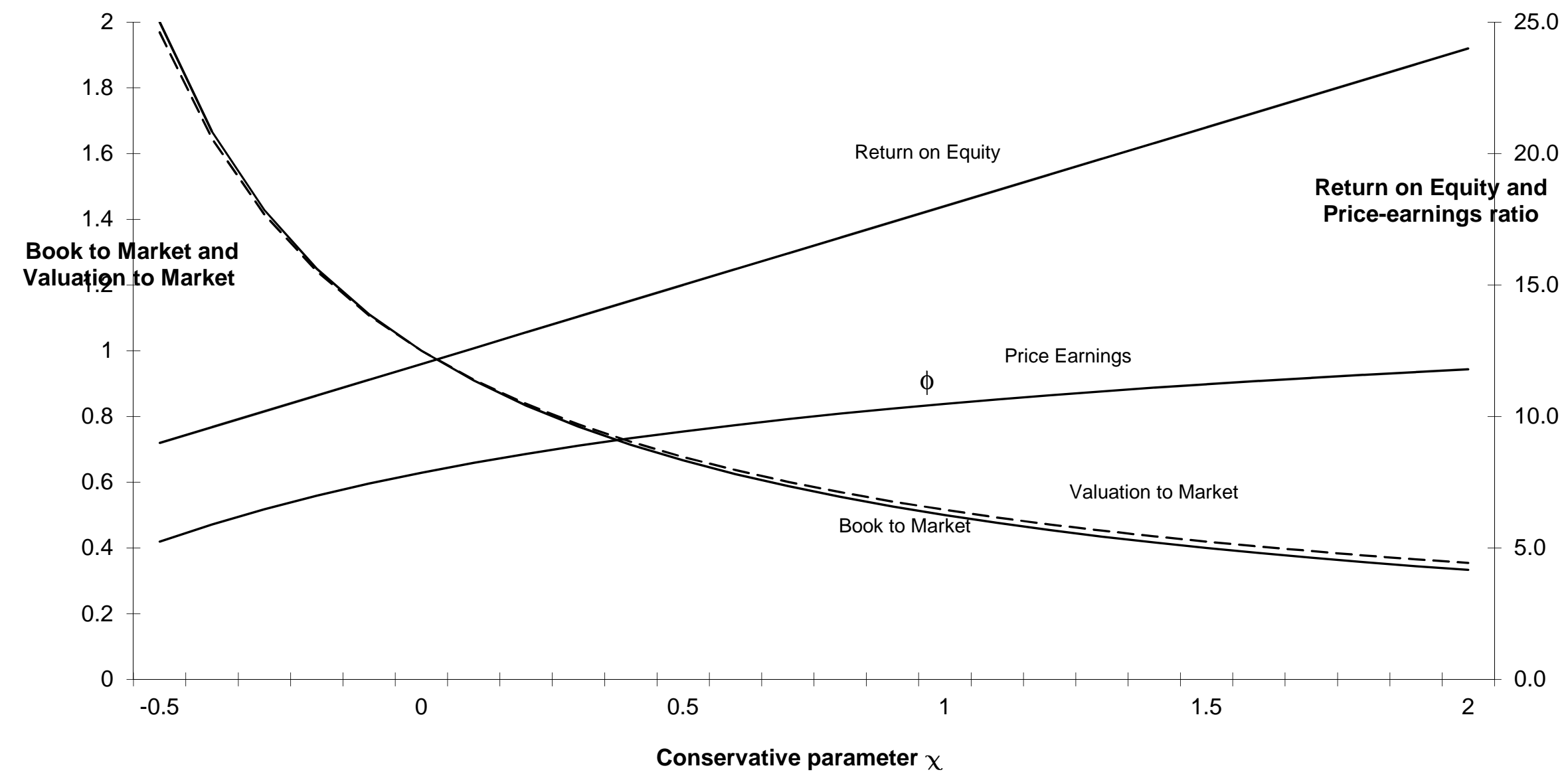

The figure shows values plotted against the conservative parameter $\chi$. On the left hand axis, the book-to-market and the ratio of the valuation-to-price, where the valuation is computed using conservative accounting data and assuming the Ohlson (1995) model of simple autoregressive behavior of abnormal earnings. Plotted against the right hand axis are the corresponding values of return on equity and the price earnings ratio. The other parameters are $\mathrm{R}=1.12, \omega=0.6$ and $\mathrm{g}=6 \%$. 
Figure 2. Comparison of the Coefficients of Book Values and Earnings by Quintiles with their Theoretical Averages
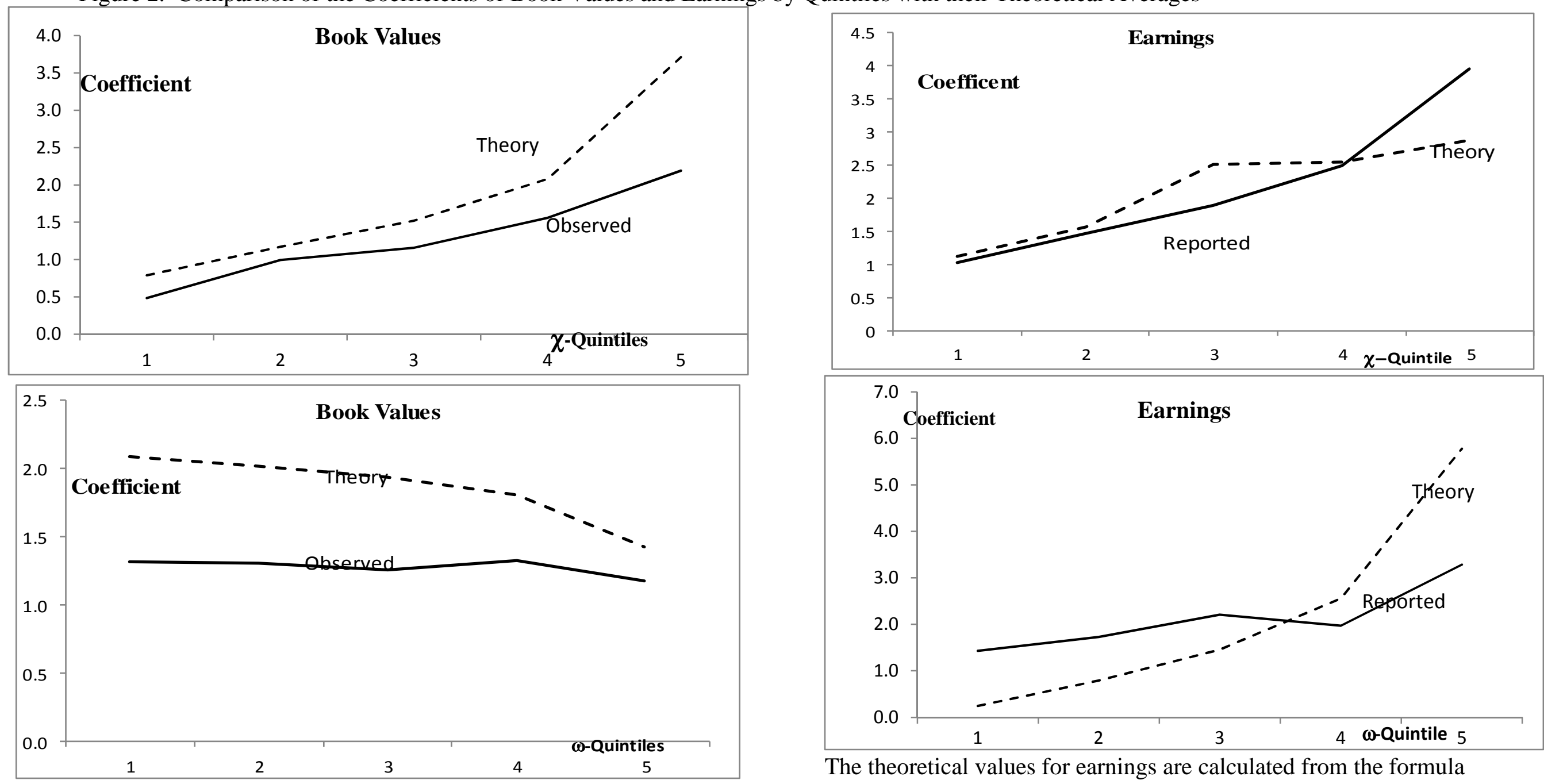

The theoretical values for book are calculated from the formula: $\frac{1}{5} \sum \frac{R\left[1-\omega\left(q_{i}\right)\right]}{R-\omega\left(q_{i}\right)}\left[1+\chi\left(q_{j}\right)\right]$ summed over $i$ or $j$ as appropriate.

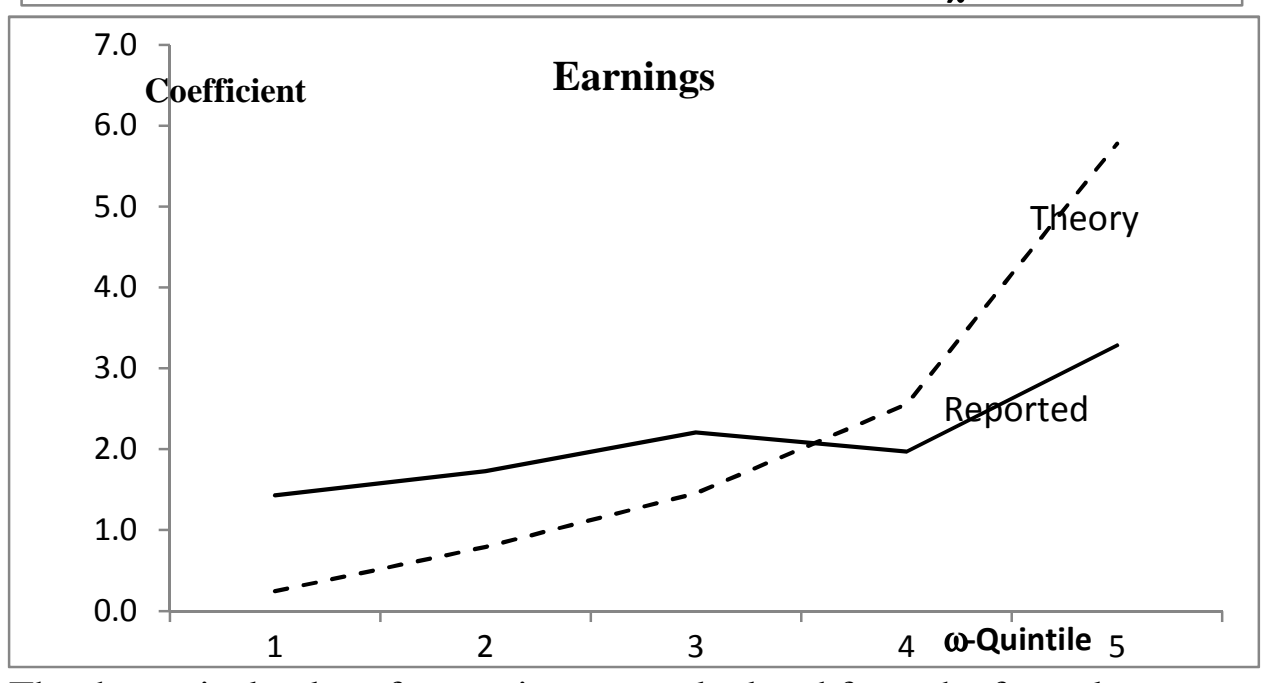

The theoretical values for earnings are calculated from the formula $\frac{1}{5} \sum_{i} \frac{R \omega\left(q_{i}\right)}{R-\omega\left(q_{i}\right)}\left[1+\chi\left(q_{j}\right)\right]$ by summing over $i$ or $\mathrm{j}$ as appropriate 
Table 1: Sample Descriptive Statistics

\begin{tabular}{|c|c|c|c|c|c|c|c|}
\hline Panel A: & Price & BPS & EPS & Dividend & $\mathrm{P} / \mathrm{B}$ & $\mathrm{E} / \mathrm{P}$ & ROE \\
\hline $\mathrm{N}$ & 116244 & 116244 & 116244 & 116244 & 116244 & 116244 & 116244 \\
\hline Mean & 14.83 & 10.000 & 0.754 & 0.348 & 2.139 & 0.048 & 0.078 \\
\hline St. Dev & 14.09 & 12.560 & 1.853 & 1.190 & 2.091 & 0.142 & 0.197 \\
\hline p1 & 1.25 & 0.498 & -4.431 & 0.000 & 0.254 & -0.494 & -0.651 \\
\hline Q1 & 5.125 & 3.398 & 0.096 & 0.000 & 0.943 & 0.014 & 0.022 \\
\hline Median & 10.52 & 6.868 & 0.587 & 0.024 & 1.509 & 0.061 & 0.106 \\
\hline Q3 & 19.69 & 12.650 & 1.347 & 0.320 & 2.516 & 0.105 & 0.173 \\
\hline p99 & 68.59 & 51.880 & 6.511 & 3.392 & 11.340 & 0.407 & 0.544 \\
\hline Panel B: & Price & BPS & EPS & Dividend & $\mathrm{P} / \mathrm{B}$ & $\mathrm{E} / \mathrm{P}$ & $\mathrm{ROE}$ \\
\hline $\mathrm{N}$ & 67251 & 67251 & 67251 & 67251 & 67251 & 67251 & 67251 \\
\hline Mean & 15.620 & 9.966 & 0.841 & 0.351 & 2.094 & 0.057 & 0.100 \\
\hline St. Dev & 14.370 & 10.260 & 1.605 & 1.030 & 1.920 & 0.124 & 0.167 \\
\hline p1 & 1.375 & 0.653 & -3.713 & 0.000 & 0.300 & -0.432 & -0.492 \\
\hline Q1 & 5.625 & 3.665 & 0.190 & 0.000 & 0.984 & 0.027 & 0.042 \\
\hline Median & 11.250 & 7.172 & 0.660 & 0.051 & 1.533 & 0.065 & 0.116 \\
\hline Q3 & 20.880 & 12.970 & 1.413 & 0.369 & 2.485 & 0.105 & 0.178 \\
\hline p99 & 69.270 & 46.880 & 5.925 & 3.074 & 10.490 & 0.365 & 0.533 \\
\hline
\end{tabular}

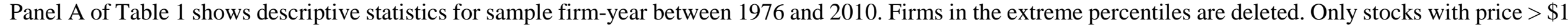

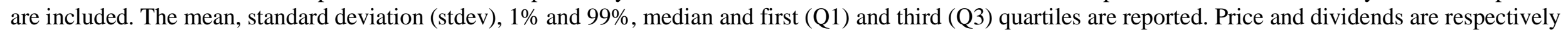
adjusted price per share and dividend per share. BPS and EPS are respectively book value per share and earnings per share based on adjusted number of shares.

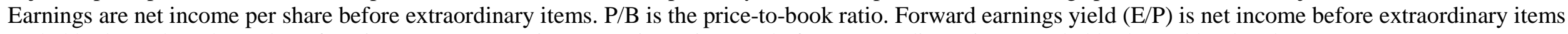
scaled by lagged market value of equity. Return on equity (ROE) is net income before extraordinary items scaled by lagged book value.

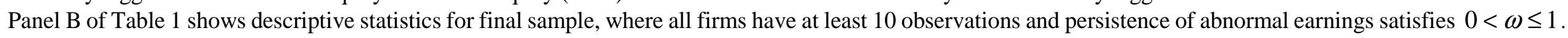


Table 2. Coefficients of Quintile Regressions Classified by the Conservatism Parameter $\chi$ and the Persistence of Abnormal Earnings $\omega$

\begin{tabular}{|c|c|c|c|c|c|c|}
\hline \multirow{2}{*}{ Book Coefficients } & \multicolumn{5}{|c|}{ Quintiles } & \multirow{2}{*}{$\begin{array}{c}\text { Row } \\
\text { Averages }\end{array}$} \\
\hline & $\omega\left(q_{1}\right)$ & $\omega\left(q_{2}\right)$ & $\omega\left(q_{3}\right)$ & $\omega\left(q_{4}\right)$ & $\omega\left(q_{5}\right)$ & \\
\hline$\chi\left(q_{1}\right)$ & 0.500 & 0.415 & 0.395 & 0.513 & 0.598 & 0.484 \\
\hline$\chi\left(q_{2}\right)$ & 0.977 & 1.073 & 1.017 & 0.998 & 0.904 & 0.994 \\
\hline$\chi\left(q_{3}\right)$ & 1.241 & 1.263 & 1.349 & 1.029 & 0.903 & 1.157 \\
\hline$\chi\left(q_{4}\right)$ & 1.719 & 1.384 & 1.519 & 1.695 & 1.473 & 1.558 \\
\hline$\chi\left(q_{5}\right)$ & 2.137 & 2.390 & 2.010 & 2.382 & 2.030 & 2.190 \\
\hline Column Averages & 1.315 & 1.305 & 1.258 & 1.323 & 1.181 & 1.277 \\
\hline \multicolumn{7}{|c|}{$\begin{array}{c}\text { Coefficients of Reported } \\
\text { Earnings }\end{array}$} \\
\hline$\chi\left(q_{1}\right)$ & 1.093 & 0.917 & 1.046 & 0.977 & 1.581 & 1.123 \\
\hline$\chi\left(q_{2}\right)$ & 1.065 & 1.282 & 1.289 & 1.812 & 2.389 & 1.568 \\
\hline$\chi\left(q_{3}\right)$ & 1.908 & 1.914 & 1.855 & 2.661 & 4.231 & 2.514 \\
\hline$\chi\left(q_{4}\right)$ & 1.530 & 2.175 & 3.189 & 2.245 & 3.595 & 2.547 \\
\hline$\chi\left(q_{5}\right)$ & 1.549 & 2.350 & 3.668 & 2.167 & 4.631 & 2.873 \\
\hline Column Averages & 1.429 & 1.728 & 2.209 & 1.972 & 3.285 & 2.125 \\
\hline \multicolumn{7}{|l|}{ Dividend Coefficients } \\
\hline$\chi\left(q_{1}\right)$ & -0.167 & 0.835 & 0.618 & 1.234 & -0.182 & 0.468 \\
\hline$\chi\left(q_{2}\right)$ & 0.605 & 0.466 & 1.600 & 0.594 & 1.650 & 0.983 \\
\hline$\chi\left(q_{3}\right)$ & 0.840 & 1.446 & 0.410 & 2.358 & 0.499 & 1.111 \\
\hline$\chi\left(q_{4}\right)$ & 1.246 & 3.954 & 2.121 & 1.889 & 1.823 & 2.206 \\
\hline$\chi\left(q_{5}\right)$ & 4.539 & 0.677 & 1.058 & 3.500 & 4.956 & 2.946 \\
\hline Column Averages & 1.413 & 1.476 & 1.161 & 1.915 & 1.749 & 1.543 \\
\hline
\end{tabular}

Table 2 reports the coefficients of book value, earnings and dividends. We first run regression on Ohlson (1995) linear information dynamic: $x_{t+1}^{\prime}=\omega x_{t}^{\prime}+\varepsilon_{x, t+1}$, for all firms with at least 10 -observations and with $0<\omega \leq 1$. We form portfolios classified by membership of the 5- $\omega\left(q_{i}\right)$ quintiles and the 5- $\chi\left(q_{i}\right)$ quintile. For each of 25-portfolio, we regress price on book, reported earnings and dividends. 
Table 3: The Median Values of the Quintile Classification of Conservatism and Persistence

\begin{tabular}{lccccc}
\multicolumn{1}{c}{ Median Values } & Quintile-1 & Quintile-2 & Quintile-3 & Quintile-4 & Quintile-5 \\
\cline { 2 - 6 } Persistence: $\omega\left(q_{i}\right)$ & 0.115 & 0.303 & 0.454 & 0.611 & 0.818 \\
Conservatism: $1+\chi\left(q_{j}\right)$ & 0.897 & 1.334 & 1.733 & 2.366 & 4.228 \\
$\quad$ & & & & & \\
$\quad$ Theoretical Average Values & & & & & \\
Book Quintiles-Conservatism & 0.787 & 1.171 & 1.522 & 2.078 & 3.713 \\
Book Quintiles-Persistence & 2.082 & 2.018 & 1.938 & 1.808 & 1.426 \\
Earnings Quintiles- Conservatism & 1.019 & 1.476 & 1.891 & 2.481 & 3.961 \\
Earnings Quintiles- Persistence & 0.244 & 0.790 & 1.458 & 2.560 & 5.776 \\
\hline
\end{tabular}

The theoretical average values of book value quintiles are calculated from the formula $\frac{1}{5} \sum \frac{R\left[1-\omega\left(q_{i}\right)\right]}{R-\omega\left(q_{i}\right)}\left[1+\chi\left(q_{j}\right)\right]$ and the theoretical average values of the earnings quintiles from the formula $\frac{1}{5} \sum \frac{R \omega\left(q_{i}\right)}{R-\omega\left(q_{i}\right)}\left[1+\chi\left(q_{j}\right)\right]$ by summing over $i$ to determine the $\chi$ - quintile and over $\mathrm{j}$ to determine the $\omega$-quintile, where $\omega\left(q_{i}\right)$ and $\chi\left(q_{j}\right)$ are the median values of the $i$ th and $j$ th quintile of persistence and conservatism respectively. 